\title{
Genetic contribution and associated pathophysiology in end-stage renal disease
}

\author{
This article was published in the following Dove Press journal: \\ The Application of Clinical Genetics \\ 2 August 2010 \\ Number of times this article has been viewed
}

\author{
Suraksha Agrawal' \\ SS Agarwal' \\ Sita Naik ${ }^{2}$ \\ 'Department of Medical Genetics, \\ Sanjay Gandhi Post Graduate Institute \\ of Medical Sciences, Lucknow, India; \\ 2Department of Clinical Immunology, \\ Sanjay Gandhi Post Graduate Institute \\ of Medical Sciences, Lucknow, India
}

Correspondence: Suraksha Agrawal Department of Medical Genetics, Sanjay Gandhi Post Graduate Institute of Medical Sciences, Raebareli Rd, Lucknow 2260I4, Uttar Pradesh, India Tel +9l 522668700800 ext. 4338, 4346,4347

Fax +9I 522 6680973/6680017

Emailsuraksha@sgpgi.ac.in

\begin{abstract}
End-stage renal disease (ESRD) or chronic kidney disease (CKD) is the terminal state of the kidney when its function has been permanently and irreversibly damaged. A wide variety of etiologies and pathological processes culminate in ESRD, and both environmental and genetic factors contribute to its development and progression. Various reports suggest that susceptibility to develop ESRD has a significant genetic component. These studies include familial aggregation studies, comparisons of incidence rates between different racial or ethnic populations, and segregation analysis. Genetic approaches have been used to identify genes that contribute to genetic susceptibility. Many studies have now been carried out assessing the contribution of specific "candidate genes", which correlate with different functions that are involved in the renal pathogenesis. Independent studies for specific associated genes have frequently provided contradictory results. This may be due, in part, to the modest contribution to genetic susceptibility which these genes impart. With the availability of different genomewide association studies, chromosomal regions harboring novel, previously unrecognized, genes that may contribute to renal diseases have been recently reported. We have focused on different genetic studies conducted on ESRD and have discussed the strength and weaknesses of these studies. The nonmuscle myosin heavy chain 9 gene (MYH9) and renin-angiotensin system (RAS) have been discussed in detail.
\end{abstract}

Keywords: genetic polymorphism MYH9, renin-angiotensin system (RAS), genome-wide analysis (WGA or GWA), end-stage renal disease

\section{Introduction}

End-stage renal disease (ESRD) is a complex disorder encompassing a large variety of phenotypes. Accurate, precise, and comparable phenotypic information is critical for gaining an in-depth understanding of the relationship between disease and genes, as well as for shedding light upon the influence of different environmental factors on different genotypes. The complexity of the phenotypic makeup of renal diseases makes this difficult. Most difficult part is diagnoses and prediction of the progression because of the complex phenotypes involved. It is equally difficult to decide on the optimal treatment for each patient. ESRD is an advanced form of chronic renal failure where renal function has declined to approximately $10 \%$ of normal prior to initiation of dialysis. There is an increasing understanding of the impact of genetic variability on the development of renal failure, which is becoming clearer and emphasizes the need to elucidate the genetic basis for renal diseases and its complications. This would lead to the better understanding of the different phenotypes observed in ESRD and would enable us to determine the genetic predisposition to terminal complications. 
The prevalence of ESRD varies in different ethnic groups. For instance, there is four fold higher risk of kidney failure among African Americans, whereas the risk is three fold in native Americans, and two fold for Hispanic Americans. ${ }^{1}$

A wide range of renal diseases lead to chronic kidney disease (CKD) and ESRD. These include monogenic disorders, such as X-linked Alport syndrome and autosomaldominant polycystic kidney disease, and many complex polygenic diseases. In the latter group, genetic factors frequently have a less direct influence on the development of CKD. However, factors such as hypertension or diabetes mellitus may cause ESRD. It is known that reduced glomerular filtration rate (GFR) is an important predictor of cardiovascular disease and death, in the high-risk groups and in the general population. ${ }^{2}$

The rate of decline of renal function is slower among individuals with renal disease following blockade of the renin-angiotensin system (RAS). This has provided evidence that activation of the RAS may promote a more rapid loss of GFR. Because the activity of the RAS is intimately related to systemic blood pressure, a number of studies have examined the relation between blood pressure and hypertension and polymorphisms in RAS-related genes with conflicting results.

Polymorphisms in other genes, specifically $\alpha$-adducin and apolipoprotein, may also promote renal function decline. Increased $\alpha$-adducin activity influences sodium handling and glomerular hemodynamics in experimental animals and is associated with hypertension in humans. ${ }^{3}$ Conversely, compared with other apolipoprotein E types, the epsilon 4 variant lowers the risk of adverse renal outcomes. ${ }^{4}$ Therefore, functional genetic variation in these genes may be involved in the loss of renal function over time. Kilis'-Pstrusińska et al demonstrated the role of other gene polymorphisms like cytokine genes (interlcukin [IL]-10, IL-4, IL-6, IL-1 $\beta$, tumor recrosis factor- $\alpha$ [TNF- $\alpha$ ], transforming growth factor- $\beta 1$ [TGF- $\beta 1$ ], monocyte chemoattractant protein [MCP], RANTES), and the gene encoding methylenetetrahydrofolate reductase in the progression of ESRD ${ }^{5}$

As there is a considerable risk of spurious associations in population-based case-control studies between a DNA polymorphism and complications, as well as outcome in ESRD, some common limitations and pitfalls need to be acknowledged. There is need for correct selection of controls, position of SNP's in terms of their effect on transcription of gene or protein expression, adequate power of the study, and results need to be replicated in the results in other cohorts. In general, results generated from studies with limited sample size ( $<200-300$ patients and control subjects) should be interpreted with caution. An option is to replicate these studies on large patient group as a dependent sample. During studying population genetics; great care should be taken to confirm that genotype distributions are not skewed, especially in the control group. Deviations from the Hardy-Weinberg (H-W) law, testing for deviations between the observed genotype frequencies and the expected ones, may indicate that the reference group does not truly represent healthy individuals. It may also indicate that genotypes might have been misinterpreted and should be rechecked. If genotypes in the patient group are not in H-W equilibrium, it may strengthen an observed correlation between genotype and phenotype. In addition, recent research and mapping of the human genome has revealed previously unappreciated heterogeneity between individuals, which should be considered when choosing single-nucleotide polymorphisms (SNPs) and interpreting SNP data. Another common limitation in SNP association studies is that the authors often do not provide any data showing an effect of the polymorphism on gene expression or protein function. Such information would strengthen the study and could reveal if an SNP is the actual cause or solely a marker cosegregating with the true functional variation and could provide an important clue for understanding the pathophysiologic mechanisms behind a clinical outcome. Furthermore, in studies evaluating the association between DNA polymorphisms and all-cause or cardiovascular deaths, it is important to correct for the impact of age, racial distribution, gender, and comorbidity (such as diabetes mellitus) in a multiple regression analysis. Finally, the results from an analysis of a DNA polymorphism in ESRD patients should be compared with the findings in nonrenal patient groups from the same ethnic background.

Recently, genetic studies have shifted to whole genome analysis (WGA) or genome-wide association (GWA) approach because it eliminates any bias in the selection of the candidate genes. One of the interesting aspects about GWA studies is that usually loci are identified that have not been previously suspected as candidate genes/loci; ${ }^{6}$ this may occur due to several reasons. The marker may be showing spurious association or the identified marker may be in linkage disequilibrium (LD) with the etiological marker, in which case the effect of different populations with different LD must be taken into account. ${ }^{7}$ Alternatively, the identified marker may be true etiological marker that has not been previously identified as having a role in the disease. In the latter two cases, novel biological pathways involved in the disease state may be uncovered, leading to a better understanding of disease processes and potentially the development of novel therapies. 
DeWan et al ${ }^{8}$ conducted a genome scan for renal clearance of creatinine. They measured creatinine clearance $(\mathrm{CrCl})$ in 466 black and 634 white hypertensive siblings from the Hypertension Genetic Epidemiology Network (HyperGen) of the FBPP. The best evidence for linkage was found on chromosome 3, both in white (at $115 \mathrm{cM}$ from 3pter) and in black individuals (at $215 \mathrm{cM}$ from 3pter). This study provided evidence of linkage for serum creatinine $(\mathrm{SrCr})$ in white individuals (at $211 \mathrm{cM}$ from 3pter) and more proximally in black individuals (at $67 \mathrm{cM}$ from 3pter). Other genome scans for measures of kidney function or nephropathy also have implicated these regions and additional regions of chromosome $3 ;{ }^{9}$ such multiplicity of linkage studies on independent sample suggests that chromosome 3 may harbor a number of genes that influence kidney function or CKD susceptibility.

Freedman etal ${ }^{10}$ reported evidence of linkage on chromosome 12 (at $112 \mathrm{cM}$ from pter) and on chromosome 19 (at $9 \mathrm{cM}$ from pter) in the HyperGen cohort. Although HyperGen, like Genetic Epidemiology Network of Arteriopathy (GENOA), ascertained sibships in which 2 or more siblings had essential hypertension diagnosed before age 60 , the HyperGen linkage analysis was conducted after pooling the black and white cohorts. The analyses of GENOA data identified "tentative" evidence of linkage for albuminuria on chromosome 12 (at $57 \mathrm{cM}$ from pter in black individuals) and on chromosome 19 (at $100 \mathrm{cM}$ from pter in white individuals); however, the considerable distances from the loci that were identified in the HyperGen analysis do not support replication.

In the two previous genome-wide scans for $\mathrm{SrCr}$ concentration, both in cohorts representative of white individuals, the strongest evidence of linkage was observed on chromosome 2 (at $145 \mathrm{cM}$ from 2 pter) ${ }^{11}$ and 4 (at $176 \mathrm{cM}$ from 4pter). ${ }^{12}$ In these studies, no linkage peaks for $\log \mathrm{SrCr}$ were observed in either of these regions. Moreover, they found no evidence of linkage for $\mathrm{SrCr}$ or for albuminuria in the chromosome 10q24-10q26 region that corresponds to the rodent renal failure locus, RF-1. ${ }^{13}$ This region had been implicated in early linkage analyses of small samples of black siblings with $\mathrm{ESRD}^{14}$ and in white pedigrees with repeated measurements of $\mathrm{CrCl}^{15}$ but not in subsequent linkage analyses for $\mathrm{SrCr}$ or albuminuria reported in the larger HyperGen cohorts. ${ }^{10}$

\section{Risk factors for developing CKD}

CKD may result from any cause of renal dysfunction of sufficient magnitude. The most common causes in the United States are diabetes mellitus followed by hypertensive nephroangiosclerosis and various primary and secondary glomerulopathies. Metabolic syndromes in which hypertension and type 2 diabetes (T2D) are present are a large and growing cause of renal damage. ${ }^{16}$ Patients with atherosclerotic vascular disease are 1.5 times more likely to develop ESRD than those without it, and patients with congestive cardiac failure are at two fold higher risk. ${ }^{16}$ Along with these factors, environmental factors also contribute to the risk. ${ }^{9}$ Various causes that may lead to CKD are shown in Table 1.

The urinary albumin/creatinine ratio (ACR), elevated $\mathrm{SrCr}$ and/or decreased $\mathrm{CrCl}$ and estimated GFR (eGFR) are major risk factors for renal and cardiovascular diseases. Epidemiological studies have reported that CKD phenotypes cluster in families, suggesting a genetic predisposition. However, studies reporting chromosomal regions influencing CKD are very limited. ${ }^{17}$ Arar et $a l^{17}$ have examined CKD (ACR, $\mathrm{SrCl}, \mathrm{CrCl}$, and eGFR) phenotypes and have shown that these were significantly heritable and showed evidence of linkage on various chromosomal locations. They have found several major chromosomal regions; the most prominent regions at $2 \mathrm{p} 25,20 \mathrm{q} 12$, and $9 \mathrm{q} 21$ were significant contributors to CKD phenotypes among low-income Mexican American families enrolled in the San Antonio Family Heart Study. This region harbors Kruppel-like factor 11 (KLF11), whose mutations tend to cause maturity-onset diabetes

Table I Major causes of chronic kidney disease

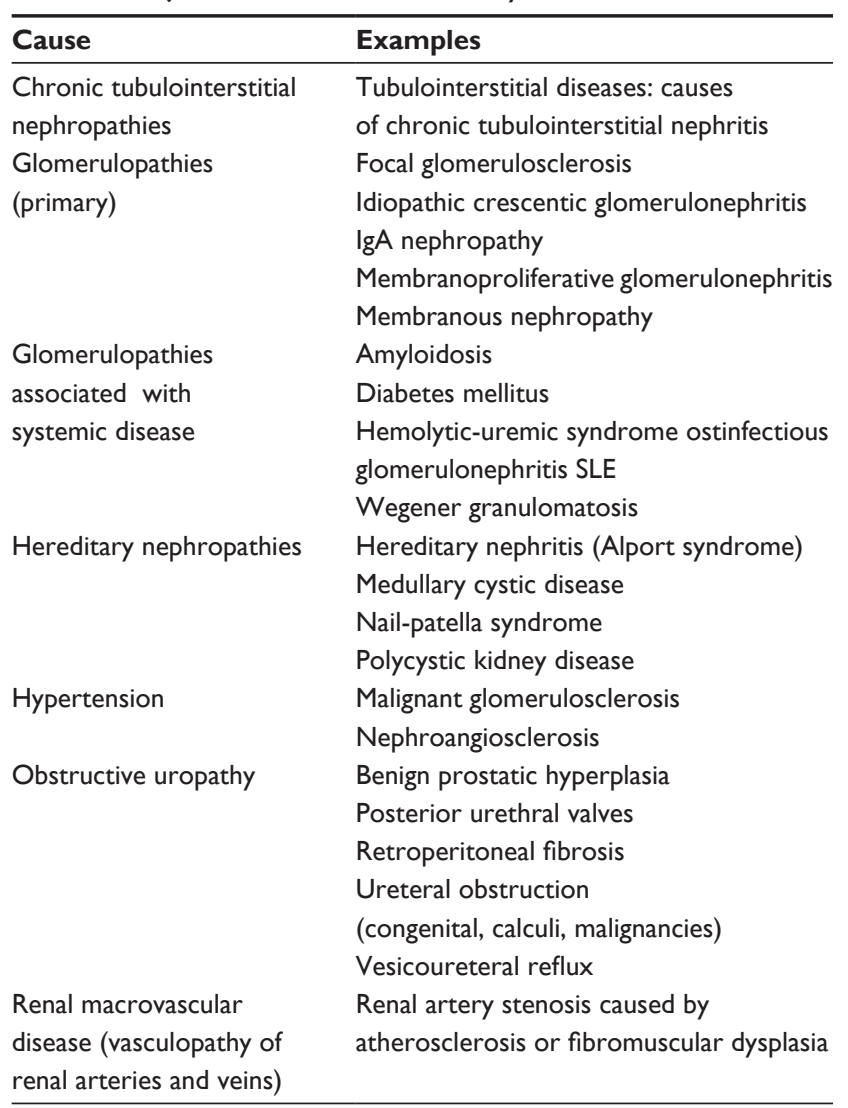


of young (MODY) type 7. The chromosomal region on chromosome 2 was consistent with all the three phenotypes (same marker D2S1780), and similarly, quantitative trait loci on chromosomes 9 and 15 were common for $\mathrm{SrCr}$ and eGFR. Altogether, their results suggest a common genetic link between decreased $\mathrm{CrCl}$, elevated $\mathrm{SrCr}$, and eGFR. This finding is expected because all the three phenotypes include $\mathrm{SrCr}$ as an important variable in their assessment. Interestingly, urinary ACR revealed distinct chromosomal regions compared to $\mathrm{SrCr}, \mathrm{CrCl}$, and eGFR. However, they pointed out that urinary ACR and the remaining CKD phenotypes may be regulated by different genes.

Some other studies exploring genomic loci regulating variation in GFR and $\mathrm{SrCr}$ have shown significant linkage on chromosomes $2,3,4,7,10,14$, and $19^{18,19}$ In a study conducted in Pima Indian sibling pairs, 9q22 was associated with diabetic nephropathy. ${ }^{20}$ The genes of potential interest in the region of 9q21-22 are cathepsin L (CTSL), implicated in the renal tubular response to albuminuria and myocardial ischemia, ${ }^{21}$ and proprotein convertase 5 (PC5), which is colocalized with $\alpha \mathrm{V}$-integrin in atherosclerotic plaques and thus may have a role in inflammation or be associated with inflammation-related phenotypes and transient receptor potential (TRP) cation channel; cathepsin and proprotein convertase 5 are a big family of proteins. There are different splice variants. These variants are characterized by a previously unknown amino terminus of 61 residues. The differences between these variants arise through splice events at three different sites. One of these splice sites might be located in the pore region of the channel as indicated by sequence alignment with other better characterized TRP channels. TRPM3, a member of TRP family, has a role in volume-regulated activity and renal calcium homeostasis. ${ }^{22}$ Mutations in one of the TRP family members, TRPC6, have been implicated in focal segmental glomerulosclerosis (FSGS). ${ }^{23}$

\section{Genetic polymorphisms and natural history of ESRD in humans}

In order to discuss the genetic predisposition to ESRD, it is important to understand the natural history of the condition and the various causative diseases or factors that lead to ESRD. ESRD may be the end result in both monogenic and polygenic diseases. Since the function of the gene related to these disorders, the pathophysiology of the disease and its extrarenal manifestations are known, investigating these genes among nonmonogenic ESRD patients may provide interesting insights into these conditions.

\section{IgA nephropathy}

$\operatorname{IgA}$ nephropathy $(\operatorname{IgAN})$ is characterized by renal IgA deposits that generate mesangial cell damage. Subsequent events that lead to kidney failure are not specific to IgAN. The natural history of the disease is variable with many affected persons having an indolent course. IgAN results from the interplay of environmental and low-penetrance genes with additive effects. Because many combinations of these factors could lead to the same pathogenic effect, there is doubt on whether accurate prediction will ever be possible for IgAN which is the most common form of primary glomerulonephritis. Variations in clinical manifestations indicate that a diagnosis of IgAN encompasses multiple disease subsets that cannot be distinguished on the basis of renal pathology or clinical variables alone. Familial forms of the disease have been reported throughout the world but are probably underrecognized because associated urinary abnormalities are often intermittent in affected family members. IgAN has complex determination, with different genes probably causing disease in different patient subgroups. ${ }^{24}$ Ethnic differences in susceptibility to IgAN, as well as interindividual variation in the disease course and prognosis, strongly argue for the crucial role of genetic factors in its pathogenesis. For example, IgAN occurs with greatest frequency in Chinese and Japanese populations but is relatively rare in individuals of African descent. ${ }^{25} \mathrm{~A}$ high frequency of IgAN has also been reported in biopsies of Zuni and Manitoba Native Americans and Australian aborigines. ${ }^{26}$ Several extended kindreds with IgAN have also been reported throughout the world, including the United States, ${ }^{27}$ France, ${ }^{28}$ Italy, ${ }^{29}$ Canada, ${ }^{30}$ Australia, ${ }^{31}$ and Lebanon. ${ }^{32}$ In all reported families, segregation of $\operatorname{IgAN}$ is consistent with autosomal dominant transmission with incomplete penetrance, although more complex genetic models are also compatible with the observed pedigrees. The incomplete penetrance is likely explained by the requirement of additional environmental or genetic factors for clinical manifestation of the disease. More recent linkage-based approaches using familial forms of the disease have identified significant or suggestive loci on chromosomes 6q22-23/IgAN1, 2q36, 4q26-31, 17q12-22, and $3 \mathrm{p} 24-23 .{ }^{33}$ The concerned genes of these loci need to be identified; their biological effects should be studied and phenotypic variations need to be explained. There is also a need to correlate genotypes more closely with the outcomes. There are partial genome scans of 80,000 SNPs and associations. These have demonstrated that IgAN is associated with polymeric immunoglobulin receptor and immunoglobulin mu-binding protein 2 (IGHMBP2) genes. ${ }^{34}$ 
Many candidate genes have been suggested, but nearly all published genetic association studies suffer from small sample size, inadequate correction for population stratification, and lack of independent replication. The most promising results reported are for glycosylation defects of $\operatorname{IgA} 1$, a subclass of IgA present in serum and mesangial deposits of IgAN patients. In healthy individuals, the hinge region of IgA1 contains up to six O-linked glycans composed of $\mathrm{N}$-acetyl-galactosamine with $\beta$-1, 3-linked galactose, both of which can be sialylated. In IgAN patients, a significant portion of the circulating IgA1 is galactose deficient (Gd-IgA1). Galactose-deficient O-linked glycans of IgA1 are potentially antigenic and may promote formation of immune complexes when recognized by naturally occurring antiglycan antibodies in the circulation. Subsequent mesangial deposition of immune complexes containing Gd-IgA1 may be responsible for glomerular injury. Interestingly, galactose deficiency appears to be specific to IgA1 molecules, and it is absent in other glycoproteins, such as $\operatorname{IgD}$, in the same patients. ${ }^{35}$ Therefore, it is most likely that the IgA1 glycosylation defect arises secondary to aberrant immunoregulation or disruption within the specific subpopulation of B cells that produce IgA1. The molecular mechanisms involved in the development and regulation of IgA1-secreting cells remain to be elucidated. The first strong evidence that IgA1 glycosylation defects may be inherited came from a study examining serum Gd-IgA1 levels in a large cohort of IgAN cases and their relatives ${ }^{36}$ The heritability or the proportion of variation in Gd-IgA1 that is attributable to genetic factors was highly significant. A clear cosegregation of high Gd-IgA1 levels and $\operatorname{IgAN}$ phenotype was observed in the pedigrees with familial disease. Moreover, Gd-IgA1 levels were significantly higher among relatives at risk for IgAN under autosomaldominant transmission compared with controls or individuals who married within families. Similar observations have recently been reported in a smaller cohort of Chinese patients with sporadic IgAN. ${ }^{37}$ The index cases with high Gd-IgA1 (majority of cases) had relatives with predominantly high Gd-IgA1. However, the index cases with low Gd-IgA1 levels had relatives with levels that were indistinguishable from healthy controls. In addition, there were many relatives of IgAN patients who had high Gd-IgA1, yet they lacked any signs of kidney disease. Taken together, it appears that GdIgA1 is neither required nor sufficient to cause the clinical disease. Rather, it should be considered one of the quantitative risk factors for IgAN, a situation that may be analogous to a serum cholesterol level in the risk of coronary artery disease. Additional cofactors may trigger and are required for full disease manifestation. For example, a recent study suggests that the individual's propensity to develop antiglycan antibodies that promote immune complex formation with Gd-IgA1 may be present as one of such cofactors. ${ }^{38}$ The above data suggest that stratification by Gd-IgA1 may be used to define subpopulations of IgAN patients with distinct disease pathogenesis. This information can be used to reduce heterogeneity in genetic studies, thus enhancing their power to detect novel susceptibility loci. The Gd-IgA1 level can also be used as a quantitative endophenotype in linkage and genetic association studies. Quantitative endophenotypes are frequently preferred in the genetic studies of a complex disease because these may be a closer reflection of a specific underlying pathogenic process. Furthermore, analysis of quantitative traits typically provides greater power compared with discrete traits.

The RAS plays an important role in promoting kidney failure. Genetic association between RAS and a homogenous group of renal failure cases, such as IgAN, would therefore provide some insights into the genetics of renal failure in general. However, association studies have produced conflicting results about genetic polymorphisms of the RAS in IgAN. This may be because of the inherent problems with such genetic studies, such as small sample size, artifacts, random events, and initial false-positive results, or there may be no association. Also, there are difficulties in the choice of a control group, as well as definition of the disease group, so that it is unambiguous, clinically relevant, and definitive. Among the three largest RAS polymorphism studies among IgAN, which show negative results, two studies have shown end-stage renal failure as the end point. ${ }^{39}$ Although most of the studies have shown no correlation of angiotensinconverting enzyme (ACE) genotypes with IgAN, a recent study by Rodríguez-Pérez et al has shown that among IgAN, there exist an interaction between ACE and eNOS gene polymorphisms, which may be a prognostic factor for renal function deterioration. ${ }^{40}$ Chemokines play an important role in the directional recruitment of inflammatory cells, and A/G polymorphism at position -2518 in the distal $5^{\prime}$ regulatory region of the chemokine MCP-1 has been shown to affect gene expression. Berthoux et al ${ }^{41}$ studied the $\mathrm{CC}$-chemokine receptor for five gene polymorphisms in primary IgAN. Their study revealed that $\mathrm{d} 32$-CCR5 polymorphism played a significant role in the progression of primary IGAN, with $\mathrm{nl} / \mathrm{nl}$ genotype being an independent protective factor for late progression toward ESRD/dialysis. 
Among Chinese patients with biopsy-proven IgAN, 2093C and 2180T alleles of megsin gene were transmitted from heterozygous parents to patients significantly more often than expected, suggesting that this gene may confer susceptibility to IgAN in other populations..$^{42}$ Megsin (SERPINB7), which is predominantly expressed in glomerular mesangium, is upregulated in IgAN. Lim et a ${ }^{43}$ found that 2093T-2180C at the $3^{\prime}$ UTR of megsin gene was associated with rapid disease progression in Korean IgAN patients. These observations are contradictory and are difficult to explain. Other recent Chinese report showed that the genotype frequency of Fcgr3b heterozygote NA1/NA $2^{44}$ and polymorphisms of the C1GALT $1{ }^{45}$ were associated with the genetic susceptibility to IgAN in the Chinese. $\mathrm{Xu}$ et a ${ }^{44}$ have also reported that higher genotype frequency of NA1/NA2 was found in IgAN patients with glomerulosclerosis or crescent formation than those without it. NA1/NA2 heterozygote of Fcgr3b is a risk factor for progression of IgAN among Chinese. To date, few genome-wide linkage studies of familial IgAN have been reported, but no causal gene has yet been identified. ${ }^{30}$

\section{Lupus nephritis}

Systemic lupus erythematosus (SLE) is a prototypic immune complex disease characterized by a variable course and outcome. There are ethnic variations in its incidence and clinical profile ${ }^{46}$ and familial aggregation of SLE, which suggests a genetic component to disease susceptibility. ${ }^{47}$ The most robust candidate genes studied to date, those encoding HLA-DR, low-affinity Fc receptors for IgG (FCGR), complement (C) 4, interferon regulatory factor 5, (IRF5), mannosebinding lectin, CTLA4, and programmed cell death-1, have shown consistent association with SLE. Other candidate genes include certain cytokines and the Fas/FasL system. Both global SLE phenotype and renal disease in patients with IgG2 anti-C1q autoantibodies have been associated with alleles of FCGR ${ }^{48}$ Recently, variation at the FCGR3B locus has also been related to renal disease in patient's making 3 FCGR genes strong candidates for association with end organ damage and ESRD. ${ }^{49}$

Alarcón et $\mathrm{al}^{50}$ determined the factors predicting the development of renal involvement and its progression to ESRD in a multiethnic SLE cohort (PROFILE). Further, Genome Wide Association studies have dramatically changed the landscape of SLE genetics; in less than 2 years time, STAT4, ${ }^{51}$ ITGAM,${ }^{52,53}$ BLK,,${ }^{54}$ PXK and KIAA1542, ${ }^{52}$ BANKI $^{55}$ and TNFAI,,$^{56,57}$ and several other genes have been identified to be associated with SLE. ${ }^{58-60}$ More susceptibility loci were reported recently in two other GWA studies. ${ }^{61,62}$ It is noteworthy that most of the studies have been conducted on patients of European ancestry with underrepresentation of other ethnicities. Recently, Yang et $\mathrm{a}^{163}$ conducted a study on 3,300 Asian SLE patients from Hong Kong, Mainland China, and Thailand, as well as on 4,200 ethnically and geographically matched controls, in which genetic variants in ETS1 and WDFY4 were found to be associated with SLE (ETS1: rs1128334, $P=2.33 \times 10^{-11}$, odds ratio [OR] $=1.29$; WDFY4: rs 7097397, $\left.P=8.15 \times 10^{-12}, \mathrm{OR}=1.30\right) .{ }^{63}$ Their study did not detect any significant disease association for $P X K$, a result that was later confirmed by an independent study on a Korean population. ${ }^{64}$ Data from their study indicated that although the risk alleles in ITGAM are rare in Asians $(<2 \%)$, they are risk factors among Asian populations and are closely related to lupus nephritis in particular.

\section{Diabetic nephropathy}

Several studies in diabetic nephropathy have shown a susceptibility locus on chromosome 18q. A polymorphism in the DNA sequence of the CNDP1 gene, which encodes the enzyme carnosinase-1, on chromosome 18q in patients with diabetes determines susceptibility to develop diabetic nephropathy. ${ }^{65}$ The substrate of carnosinase-1, L-carnosine, is a potent inhibitor of oxidative stress and the formation of advanced glycation end products, which may thus act as a cytoprotective factor during diabetes. It was postulated that opposing mechanisms, ie, hyperglycemia vs the action of protective factors such as L-carnosine, determine the net outcome of diabetic nephropathy. ${ }^{65}$

Savage et $\mathrm{a}^{66}$ have assessed $1,111 \mathrm{nsSNPs}$ in association with diabetic nephropathy in 1,711 individuals with type 1 diabetes (894 cases, 817 controls). A number of SNPs demonstrated a significant difference in genotype distribution between groups before applying statistical correction but not after correction for multiple testing. Furthermore, neither subgroup analysis (diabetic nephropathy with ESRD or diabetic nephropathy without ESRD) nor stratification by duration of diabetes revealed any significant differences between groups.

To conduct a statistically robust study that provides genome-wide coverage for detection of common variants that may have relatively small, but pathogenically significant, effect on risk of diabetic nephropathy in type 1 diabetes has been proved by conducting the genome-wide scan, which was supported by the Genetic Association Information Network initiative. ${ }^{67}$

Pezzolesi et $\mathrm{l}^{167}$ have presented data on (1) results of this GWA scan in the GoKinD collection, (2) replication of 
the significant associations in this scan with time to onset of diabetes-associated complications (severe nephropathy) in the Diabetes Control and Complications Trial (DCCT)/ Epidemiology of Diabetes Interventions and Complications (EDIC) study, and (3) characterization of expression of the identified candidate diabetic nephropathy genes in normal human cell lines.

Leak et $\mathrm{al}^{68}$ have carried out a linkage scan of 638 African American affected sibling pairs with T2D enriched for ESRD. Ordered subset linkage analysis revealed a linkage peak on chromosome $7 \mathrm{p}$ in the subset of families with earlier age of T2D diagnosis. The most significant association was observed between ESRD age of diagnosis and SNP rs730497, located in intron 1 of the GCK1 gene (recessive T2D ageadjusted $P=0.0006$ ). Nominal associations were observed with GCK1 SNPs and T2D age of diagnosis (BMI-adjusted $P=0.014-0.032$ ). Also, one IGFBP1 and four IGFBP3 SNPs showed nominal genotypic association with T2D-ESRD $(P=0.002-0.049)$. Correction of multiple tests resulted into only rs 730497 as a significant SNP. A variant of the GCK1 gene, rs730497, appears to play a role in susceptibility to earlier age of ESRD onset in African Americans. This may not represent the "true" casual variant but may be in LD with a functional SNP. It is plausible that multiple rare variants in this region of the gene may contribute to this phenotype. In addition, other candidates under the LOD-1 interval, including the growth factor receptor-bound protein 10 (GRB10) and IGF2 mRNA binding protein 3 (IGF2BP3), warrant investigation. ${ }^{68}$

\section{Monogenic diseases and renal involvement}

The development of kidney is a complex process and is governed by large number of signaling pathways, including the Pax/Eya/Six genes, as well as Lim 1 and Odd1. The uteric outgrowth and branching morphogenesis are controlled by the Ret/Gdnf pathway. In mouse, Wnt9b and Wnt4 genes are crucial for aggregation and transformation of metanephrogenic mesenchyme into tubular epithelium. If separated from the uteretic bud, mesenchymal cells die. FGF2 and BMP7 are the two factors secreted by the ureteric bud that prevents apoptosis and promote aggregation. The competence to respond to uteric bud inducers is believed to be regulated, among other genes, by $W T 1$, a transcription factor originally found to be mutated in heritable form of childhood kidney tumor. Besides leading to tumors, specific mutations in WT1 can result in Denys-Drash syndrome, a condition characterized by Wilms tumors, and nephrotic syndrome (severe albuminuria) leading to ESRD before the age of 3 years, and pseudohermaphrodit- ism with children has either ambiguous external genitalia or a normal female phenotype with an XY karyotype.

Congenital anomalies of the kidney and urinary tract (CAKUT), including vesicoureteric reflux (VUR [MIM 193000]), are major causes of ESRD in childhood. Vats et $\mathrm{al}^{69}$ reported evidence for a locus on $13 \mathrm{q} 33 \mathrm{q} 34$ associated with CAKUT. They performed the deletion mapping of chromosome $13 \mathrm{q}$ in four children with CAKUT using 31 microsatellite markers from the patients and their parents. A locus for renal malformations including VUR on chromosome 13q33-34 was studied. Its mRNA expression of the positional candidate genes was compared with sequences in electronic databases in silico. Further, it was studied in adult and fetal mouse kidneys using reverse-transcription polymerase chain reaction. The children (three girls; age range, 5-17 years) had varying severity of developmental delay and other organ system involvement. The spectrum of CAKUT included high-grade VUR $(n=2)$, renal dysplasia $(\mathrm{n}=2)$, and hydronephrosis $(\mathrm{n}=1)$. Both the children with VUR had evidence of renal failure, with one of them developing ESRD. Deletion mapping identified a 7-Mb critical region flanked by markers D13S1311 and D13S285. There are 33 genes (12 known; 21 computer predicted) in this region. In silico expression studies showed matches for 14 of these genes in the kidneys and 10 in the bladder expressed sequence tags databases. Studies on mouse kidney showed that of the 24 genes examined, several had variable expression through the different stages of renal development, whereas five were not expressed at all. They have reported a new locus on chromosome 13q33q34 that can be associated with VUR with several genes showing mRNA expression patterns that suggest their potential involvement in renal/urinary tract developmental anomalies.

CAKUT is most likely a polygenetic condition. In the only genome-wide study of seven families with nonsyndromic VUR, a linkage to chromosome 1 has been reported..$^{70}$ It is interesting that two of the seven pedigrees did not link to this locus, suggesting genetic heterogeneity for VUR. SannaCherchi et $\mathrm{al}^{71}$ analyzed seven large European families with VUR. They studied markers on chromosomes 1p13, 3p12, $6 \mathrm{p} 21,10 \mathrm{q} 26$, and $19 \mathrm{q} 13$ but reported no linkage to any of these loci. These data demonstrated substantial genetic heterogeneity of VUR and findings seen on 13q33 locus. There may be additional but only moderate support for a 13q33 locus for renal diseases. ${ }^{72}$ It is interesting that Feather et $\mathrm{al}^{70}$ in their report also identified 12 additional possible loci for VUR with a $P<0.05$, including a locus on 13q. The cumulative parametric logarithm of odds (LOD) score for the 13q locus (in 
the region of $96-113 \mathrm{cM}$ ) in that study was 2.08 (nonparametric linkage score $=2.37 ; P=0.02$ ), when all of the families that were not linked to chromosome 1 were analyzed. Although these LOD scores were small, their data are at least suggestive of a possible locus on chromosome 13 that seems to overlap with the locus described in this report. Finally, in an attempt to map the genes that predispose to the common causes of ESRD, a genome-wide scan in 1,023 individuals with CKD from 483 black families was performed by Freedman et al. ${ }^{72}$ Their results showed a modest evidence of linkage to 13q33.3 near D13S796 on multipoint, nonparametric linkage analysis (LOD = 1.72). Incidentally, marker D13S796 is in the middle of the critical 13q33 region. Although there are no data available on the presence of VUR in the Freedman et al study, it is conceivable that gene(s) in this region may contribute to both renal function and anatomy. VUR may be associated with hypertension. ${ }^{73}$ This locus, therefore, may be worthy of further examination in both syndromic and nonsyndromic VUR. In a linkage study of 609 individuals from 129 Irish families with one affected member for 4,710 SNPs. Among linkages at chromosome 2q37, (NPL is maximum at $2.67(P=0.001)$ and among linkages at 10q26 and 6q27, several smaller peaks were seen. Analysis of a subset without any additional features, such as duplex kidneys, yielded a maximum NPL score of $4.1(P=0.001)$, reaching levels of genome-wide statistical significance. ${ }^{74}$ A recent study by Cordell et $\mathrm{al}^{75}$ using whole genome scan in primary, nonsyndromic vesicoureteric reflux revealed a modest evidence of linkage but no clear overlap with previous studies. They tested for the previously reported studies but did not detect association with 6 candidate genes (AGTR2, HNF1B, PAX2, RET, ROBO2, and UPK3A). This study revealed that $\mathrm{rs} 11083021$ is in intron 3 of OSBPL1A, which encodes oxysterol binding protein-like 1A; a member of the OSBP family of intracellular lipid receptors is associated with nonsyndromic vesicoureteric reflux. Five SNPs were detected in the Slovenian analysis: rs4895183 and rs17144806, and rs17175928 and rs16963279. These are intronic SNPs in genes of unknown function: DTWD2, C10orf72, and FAM59A, respectively. rs2102860 is in LD with RTP4, which encodes a golgi chaperone that plays a role in the movement of $\mu-\delta$ opioid receptor to the cell surface membrane and may be involved in membrane targeting of other $\mathrm{G}$ protein-coupled receptors. rs 1983167 and rs7881785 both are in LD with the monoamine oxidase inhibitors MAOA and MAOB. rs12604993 is in LD with TXNL4A (thioredoxin-like 4A). Two SNPs were identified in the family-based analysis, rs1696803 and rs11029158, and two were identified in the case-control analysis of the UK cases, rs11599217 and rs17306391. These are not in LD with transcripts. Family-based analysis detected associations with one SNP in the UK families, with three SNPs in the Slovenian families and with three SNPs in the combined families. A case-control analysis detected associations with three additional SNPs. The results of this study, which is the largest to date investigating the genetics of reflux, suggest that major loci may not exist for this common renal tract malformation within European populations. Weng et $\mathrm{al}^{76}$ have identified a recessive gene for primary vesicoureteral reflux. This gene maps to chromosome 12p11-q13. They performed a genome-wide linkage scan in 12 large families segregating pVUR, comprising 72 affected individuals. To avoid potential misspecification of the trait locus, they used a parametric linkage analysis using both dominant and recessive models. Analysis under the dominant model yielded no signals across the entire genome. In contrast, they identified a unique linkage peak under the recessive model on chromosome 12p11-q13 (D12S1048), which was further confirmed by fine mapping. This interval achieved a peak heterogeneity LOD score of 3.6 with $60 \%$ of families linked. This heterogeneity LOD score improved to 4.5 with exclusion of two high-density pedigrees that failed to link across the entire genome. The linkage signal on chromosome $12 \mathrm{p} 11-\mathrm{q} 13$ originated from pedigrees of varying ethnicity, suggesting that recessive inheritance of a high-frequency risk allele occurs in pVUR kindreds from many different populations. In conclusion, this study identifies a major new locus for pVUR and suggests that in addition to genetic heterogeneity, recessive contributions should be considered in all pVUR genome scans. ${ }^{76}$

\section{Polycystic kidney disease}

The phenotypes that are associated with the autosomal dominant (ADPKD) and autosomal recessive (ARPKD) forms of polycystic kidney disease (PKD) are highly variable in penetrance. ADPKD is genetically heterogeneous, and two genes, PKD1 (16p13.3) and PKD2 (4q21), have been identified. $P K D 1$ is the major locus, accounting for approximately $85 \%$ of families. ${ }^{77}$ Further, genetic heterogeneity has been suggested by unlinked families but no further genes have been identified, and indeed, it is not sure whether the $P K D 3$ exists. ${ }^{78}$ PKD1 has 46 exons and encodes a large protein, polycystin-1 (4,303 amino acids). Exons 1-33 lie in a complex genomic region that is reiterated approximately six times further proximally on chromosome 16. ${ }^{79}$ Similarity between $P K D 1$ and these pseudogenes means that locus-specific amplification methods are required to analyze $P K D 1 .{ }^{80}$ PKD2 has 15 exons and encodes polycystin-2 (968 amino acids). ${ }^{81}$ 
A high level of allelic heterogeneity is found for both genes, with a total of 270 different mutations reported for $P K D 1$ and 73 for $P K D 2$. More complete information in the ADPKD Mutation Database (http://pkdb.mayo.edu) describes 298 PKD1 and 106 PKD2 mutations. The vast majority of mutations are unique to a single family. For $P K D 1,200(67 \%)$ mutations are definitely pathogenic (nonsense, frameshift, or splicing) and 98 (33\%) are missense or other in-frame events. For PKD2, a larger proportion of mutations are truncating, 97 (91.5\%), and only nine (8.5\%) are in-frame. In a recent screen of 202 well-characterized probands with ADPKD (the Consortium of Radiologic Imaging Study of PKD population), comprehensive mutation analysis of both genes identified a probable mutation in almost $90 \%$ of cases This study involved a systematic algorithm for scoring the likely pathogenicity of missense and other typical changes. Although these methods are far from perfect for mutation prediction, they do show the prospects for molecular diagnostics in ADPKD. Although gene-based diagnostics are not necessary in every patient with ADPKD (renal imaging is a reliable diagnostic tool in most cases), it can be helpful in childhood cases with unknown etiology and critical for young living-related donors for whom imaging data are less reliable. It is likely to become more important as therapies are developed.

There is little evidence of genetic heterogeneity in typical ARPKD cases. The disease gene, PKHD1 (6p21), has 67 exons and encodes the large protein fibrocystin (4,074 amino acids). ${ }^{82}$ As in ADPKD, many different PKHD1 mutations cause ARPKD. To date, 305 different mutations are listed in the ARPKD/PKHD1 Mutation Database (http://www.humgen.rwth-aachen.de1), accounting for more than 700 mutant alleles. In this case, only approximately $40 \%$ are predicted to truncate the protein, with approximately $60 \%$ missense. Several studies have used detailing algorithms to assess the pathogenicity of these changes to aid their use for diagnostics. ${ }^{83,84}$ Approximately one-third of PKHD1 mutations are unique to a single family. Some ancestral mutations are common in particular populations, and one mutation, T36M, of Northern European origin accounts for approximately $17 \%$ of mutant alleles. ${ }^{85}$ Molecular diagnostics for ARPKD is important for prenatal testing, including preimplantation genetic diagnostics, and for establishing a firm diagnosis. ${ }^{86}$

Genetic modifiers have been mapped in mouse models of recessive $\mathrm{PKD}$, and in one case, the Kif12 gene was identified as a possible modifier in the $c p k$ mouse ${ }^{87}$ Another possible modifying factor is the MODY5-associated protein HNF1 $\beta$ that regulates $P K H D 1$ expression by binding to its proximal promoter. ${ }^{88}$ Song et a ${ }^{89}$ have shown that upregulation of Wnt/ beta-catenin, pleiotropic growth factor/receptor tyrosine kinase (eg, IGF/IGF1R, FGF/FGFR, EGF/EGFR, and VEGF/ VEGFR), and G protein-coupled receptor (eg, PTGER2) signaling was associated with renal cystic growth. By integrating these pathways with a number of dysregulated networks of TFs (eg, SRF, MYC, E2F1, CREB1, LEF1, TCF7, HNF1B/ HNF1A and HNF4A), they suggested that epithelial dedifferentiation accompanied by aberrant activation and cross talk of specific signaling pathways may be required for PKD1 cyst growth and disease progression. Pharmacological modulation of some of these signaling pathways may provide a potential therapeutic strategy for ADPKD.

\section{Nephronophthisis}

Nephronophthisis (NPHP; MIM 256100) constitutes the most frequent genetic cause of ESRD in children and young adults. Characteristic histologic findings in NPHP are renal interstitial fibrosis, interstitial cell infiltrates, and tubular atrophy with cyst development at the corticomedullary junction. All NPHP variants share the described renal histology pattern with the exception of infantile NPHP (type 2), which shows additional features reminiscent of autosomal dominant or recessive PKD, such as kidney enlargement, absence of the tubular basement membrane irregularity characteristic of NPHP, and presence of cysts outside the medullary region.

NPHP is a genetically heterogeneous disorder. Six genes causing NPHP have been identified by positional cloning: NPHP 1 on chromosome $2 \mathrm{q} 13,{ }^{90}$ NPHP 2 on $9 \mathrm{q} 22,{ }^{91} N P H P 3$ on 3q22, ${ }^{92}$ NPHP4 on $1 \mathrm{p} 36,{ }^{93}$ NPHP5 on $3 \mathrm{q} 21.1,{ }^{94}$ and NPHP6 on $12 \mathrm{q} 21 .{ }^{95}$ Approximately $25 \%-30 \%$ of all patients with NPHP show large homozygous deletions of the NPHP1 gene. ${ }^{96}$ The gene products of NPHP1 through NPHP4 are known to interact. ${ }^{91}$

The gene product of NPHP1, nephrocystin-1, encodes a docking protein that interacts with components of cell-cell and cell-matrix signaling, such as p130Cas, filamin, tensin, and focal adhesion kinase $2 .{ }^{97}$ It also interacts with the gene product of NPHP4, nephrocystin-4, mutations in which cause NPHP type $4^{93}$. NPHP is a good example of oligogenic inheritance. Fiskerstrand et $\mathrm{a}^{98}$ carried out homozygositybased mapping for renal-hepatic-pancreatic dysplasia by microarray. They have demonstrated a single, large homozygous region of $21.16 \mathrm{Mb}$ containing $\sim 200$ genes on the long arm of chromosome 3 . This region contained 2 known ciliopathy genes: NPHP 3 (adolescent nephronophthisis) and IQCBI (NPHP5), which are associated with Senior - Löken 
syndrome. In NPHP3, homozygosity for a deletion of the conserved splice acceptor dinucleotide (AG) preceding exon 20 was found in NPHP3 homozygosity. These authors concluded that NPHP3-null mutations cause renal-hepaticpancreatic dysplasia. Their study demonstrates how genes for rare and genetically heterogeneous recessive conditions may be identified by homozygosity mapping using SNP arrays in the routine clinical setting. Hildebrandt et $\mathrm{al}^{99}$ have shown that mutations in NPHP genes cause defects in signaling mechanisms that involve the noncanonical Wnt signaling pathway and the sonic hedgehog signaling pathway, resulting in the defect of planar cell polarity and tissue maintenance. Nephrocystins are highly conserved in evolution, thereby allowing the use of animal models to develop future therapeutic approaches.

\section{Hereditary FSGS}

FSGS is a clinicopathologic syndrome characterized by proteinuria, usually of nephrotic range. Early in the disease process, there is a pattern of focal and segmental glomerular sclerosis that is focal, involving a subset of glomeruli, and segmental, involving a portion of the glomerular tuft. As the disease progresses, a more diffuse and global pattern of sclerosis evolves. The condition is characterized by alterations of the podocytes as seen by the major ultrastructural findings.

FSGS is a nonspecific histopathologic finding in several renal disorders characterized by albuminuria and progressive decline in renal function. Although it is often secondary to other disorders including obesity, hypertension, diabetes mellitus, and HIV infection, FSGS also appears as an isolated idiopathic condition. The genetic contribution to the etiology of idiopathic FSGS is indicated by reports of its occurrence in multiple members of families. Both autosomal dominant and recessive patterns of inheritance have been described.

Autosomal dominant FSGS can be caused by mutations in the gene encoding $\alpha$-actinin-4 (ACTN4) and transient receptor potential cation channel, subfamily C, member 6 (TRPC6). Mutations in NPHS1 (Nephrin) cause the Finnish form of congenital nephrosis, and mutations in the NPHS2 (Podocin) cause steroid-resistant nephrotic syndrome. Both result in a clinical picture of congenital FSGS and are transmitted in recessive fashion. Other genes implicated in glomerulosclerosis with nephrotic range proteinuria include $\mathrm{CD} 2$-associated protein (CD2AP), Laminin beta-2 (Lamb2), LIM Homeobox transcription factor 1 BETA (LMX1B) and WT1.

Brown et al ${ }^{100}$ recently reported in Nature Genetics another gene causing adult-onset FSGS with autosomal dominant inheritance. They used two large families with sev- eral affected family members in three and four generations, respectively. The phenotype was defined by biopsy-proven FSGS, ESRD without cause or macroalbuminuria $>250 \mathrm{mg} / \mathrm{g}$ creatinine. Genome-wide linkage analysis defined the gene locus on chromosome 14q32. Screening 15 genes lead to identification of nonsynonymous (amino acid changing) mutations in the inverted formin 2 (INF2) gene in all affected family members. The investigators sequenced 91 unrelated individuals with idiopathic FSGS and identified nine additional families with mutations in INF2, all segregating with disease. Mutations were not seen in more than 600 control individuals. Most mutations were identified in the highly conserved exon 4, which encodes for diaphanous inhibitory domain (DID) of INF2.

The phenotypes in families with INF2 mutations shared certain features. Affected individuals presented in early adolescence or adulthood, typically with moderate albuminuria. Although some family members had nephrotic-range albuminuria, none of the affected individuals showed the spectrum of clinical findings that constitutes nephrotic syndrome. Microscopic hematuria and hypertension were noted in some affected individuals. Disease and albuminuria appeared to be progressive and often lead to ESRD. INF2 is a member of the formin family of actin-regulating proteins that accelerate both polymerization and depolymerization of actin in vitro. Most mutations in FSGS were identified in DID, an autoinhibitory domain. In the most extensively studied diaphanous formin, mDial, and the interaction of the N-terminal DID domain with the C-terminal diaphanous activating domain (DAD) inhibit mDial function. ${ }^{100}$

INF2 is highly expressed in podocytes. Electron microscopy of kidney biopsy material from an individual with INF2 mutation showed irregular podocyte foot-process morphology and prominent actin bundles. In addition, transfection studies of overexpressed wild-type and FSGS-associated mutant forms of INF2 indicate differences in the subcellular localization of the mutant and wild-type proteins, as well as differences in the pattern of distribution of actin. The precise mechanism by which actin behavior is disrupted in the presence of INF2 alterations in vivo is unclear and has yet to be defined. ${ }^{100}$

\section{Nonmuscle myosin heavy chain 9 gene and kidney disease}

The myosin heavy chain 9 (MYH9; MIM *604933) gene, located on chromosome 15 , is approximately $110 \mathrm{~kb}$ in length with 41 exons. ${ }^{101}$ The structure of the gene is shown in Figure 1. Its protein product MYH9 is a nonmuscle MYH, 
class II, and isoform type A protein responsible for moving actin filaments in cells, ${ }^{101}$ which is abundantly expressed in the kidney, liver, and platelets. It is highly conserved in several mammalian species and is very similar to other nonmuscle myosin isoforms ${ }^{102}$ Nonmuscle myosin heavy chain 9 proteins carry out variety of cellular functions, such as cellular polarity, architecture, and trafficking. ${ }^{102,103}$ Mutations in MYH9 are associated with several Mendelian conditions and autosomal dominant disorders, such as Epstein syndrome, Fechtner syndrome, May-Hegglin anomaly, Sebastian syndrome, and an autosomal dominant form of deafness. ${ }^{104}$ To date, more than 30 MYH9 mutations have been described. Mutant alleles exert their effect by haploinsufficiency or by negative interference with the wildtype protein inactivating their biological function. ${ }^{105}$

A novel mutation, c.Ala95Asp, has been reported by de Rocco et $\mathrm{al}^{106}$ in the $M Y H 9$ gene in a family with 8 affected individuals suffering from macrothrombocytopenia and hearing impairment. Since the mutation affects the motor domain of the protein, it is likely to be associated with a severe phenotype, and this family should be carefully followed up and their renal status should be monitored, even though the affected members do not seem to be at risk of early kidney disease.

Within the kidney, MYH9 expression occurs in the podocytes, peritubular capillaries and tubules of the glomerulus. Aggregation of abnormal myosin and damage to cytoskeleton of the podocyte and tubular cells could lead to progressive kidney disease. However, it remains to be determined how sequence variation in MYH9 directly results in the development and progression of nondiabetic kidney disease. Nonmuscle myosin, like muscle myosin, is assembled from separately coded heavy and light chains and binds to actin to perform intracellular motor functions. ${ }^{107}$ Under light microscopy, kidney biopsy early in the course of the disease in an individual with MYH9 mutation was found to be normal, whereas under electron microscopy, focal podocyte foot process effacement and loss of podocyte slit diaphragms, indicative of podocyte injury, are seen. The Myh9 knockout mouse shows embryonic lethality, whereas heterozygous mice have apparently normal phenotype other than hearing loss with incomplete penetrance. Myosin IIA has been localized to podocyte and possibly mesangial cells. ${ }^{108}$ Other mutations affecting podocyte proteins that interact with the actin cytoskeleton, including $\alpha$-actinin- $4, \mathrm{CD} 2$-associated protein, and synaptopodin have been associated with podocyte injury and FSGS in humans or experimental animals. This suggests that an intact actin cytoskeleton is required to maintain normal podocyte cytoarchitecture and filtration barrier function.

MYH9 gene is also associated with human immunodeficiency virus (HIV)-associated FSGS and ESRD due to hypertension in African Americans. This has lead to understanding of etiology of nephropathy. ${ }^{109,110}$ The ACE inhibitors are not very effective if the individual is carrying $M Y H$ gene. The risk haplotype is observed in $60 \%$ of African Americans (African decent settled in America) and 4\% of European (Americans) for developing ESRD due to hypertension.

In the first effort to search for association with quantitative measures of clinical kidney disease in a sample not enriched for nephropathy, four SNPs comprising the major MYH9 risk haplotype (the E1 haplotype) were analyzed in European Americans and African Americans with subclinical nephropathy. ${ }^{111}$ The participants were recruited from HyperGEN hypertensive sibships (including mild and severe hypertension) selected from families with two or more hypertensive siblings diagnosed before 60 years of age, as well as their adult offspring (offspring were not necessarily hypertensive or taking antihypertensive medications). Hypertension was graded and renal replacement therapy was an exclusion criterion. In contrast to prior reports, the $M Y H 9$ E1 haplotype was not as strongly associated with albuminuria as it was with severe kidney disease and ESRD. These results

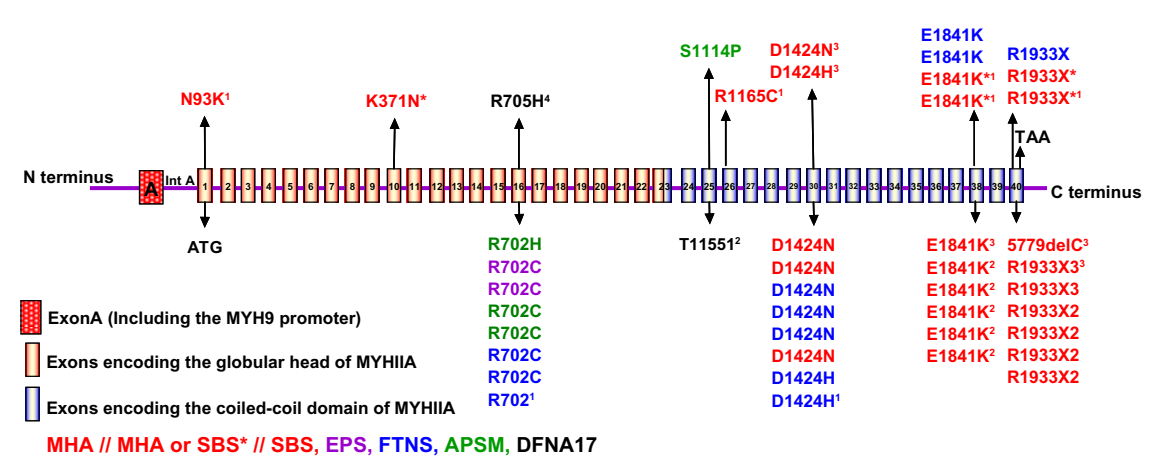

Figure I Schematic representation of MYH9 genomic structure (not drawn to scale) and the spectrum of mutations identified in the MYH9 gene. The 40 coding exons and the promoter (noncoding exon A) are represented by vertical colored bars. Intron A (Int A) contains enhancer elements. 
suggest that most hypertensive African Americans are not at extreme risk for developing subsequent nephropathy, a result that has clearly been demonstrated in the Multiple Risk Factor Intervention Trial and Hypertension Detection and Follow-up Program cohorts. Longitudinal studies in African Americans subjects with $M Y H 9$ risk alleles are required to determine whether high blood pressure is the result of a primary kidney disease such as FSGS or whether nephrosclerosis with albuminuria develops in hypertensive subjects homozygous for MYH9 risk SNPs and haplotypes. Further, this study revealed that $M Y H 9$ is strongly associated with biopsy-proven idiopathic and HIV-associated FSGS and clinically diagnosed 'hypertension-associated' ESRD in African Americans. However, its role in type 2 diabetes mellitus (T2DM)-associated ESRD is not very clear. These disparate kidney diseases often cluster in African American families, with family members having ESRD attributed to T2DM.

It is possible that $M Y H 9$ polymorphisms are associated with CKD in a subset of T2DM-associated ESRD cases, particularly in multiplex-affected families. Although initial analyses of $M Y H 9$ and DM-associated ESRD did not reveal any association, ${ }^{112}$ another study was conducted on a larger cohort of African Americans with clinically diagnosed T2DM-ESRD. This study revealed a unifying major genetic factor. African Americans develop ESRD attributed to diabetes mellitus four times more often than European Americans, although MYH9 associations are clearly weaker in diabetic, relative to nondiabetic, forms of ESRD. It is interesting to note that in a recent report, regardless of the actual underlying histology, African Americans who appear to have T2D-associated ESRD on clinical grounds may have MYH9-associated disease. Evaluation of renal biopsies in diabetic subjects with early stages of nephropathy may be required to clarify whether the disease is $M Y H 9$-associated FSGS or classic DN. Among African Americans who have longstanding diabetes mellitus and albuminuria, is $\mathrm{MYH9}$ associated with the classic histological changes attributed to DN (eg, diffuse thickening of the glomerular basement membranes, mesangial expansion and/or nodular glomerulosclerosis) or with diseases in the FSGS-global glomerulosclerosis spectrum? The different frequencies of genetic variants between African Americans and European Americans have potential implications for future screening strategies for African Americans with hypertension. These studies indicate that the MYH9 gene is the location of the disease-causing variations, but the specific variants have not yet been definitively identified. Various studies available on MYH9 in literature are summarized in Table 2.
Nelson et $\mathrm{al}^{119}$ carried out the dense mapping of MYH9 and found that there exist a strongest associations of kidney disease to the region of introns 13-15. The strongest SNP associations reported by them are for three SNPs in introns 13-15 (P 1/4 4 10227 for rs 2413396 in intron 14 for combined FSGS, P $1 / 43$ _ 10222 for rs 5750250 in intron 13 for H-ESKD). The multiple associations of SNPs spanning MYH9 are largely due to extensive LD within and between haplotype blocks; however, this study and others suggest that multiple SNPs within the MYH9 gene predict renal disease. ${ }^{112,120}$ They found that independent associations remain, after conditioning on rs2413396 or rs5750250 and controlling for ancestry for SNPs, in introns 1, 12, 33, and exon 40 (encoding the 30-UTR). An independent association of rs 11912763 in intron 33, in the region previously reported in Freedman et al, ${ }^{112}$ is notably robust.

Another study ${ }^{120}$ describes generally similar, and correspondingly highly significant, associations for MYH9 SNPs and haplotypes with hypertensive ESKD in a New York-based Hispanic cohort. They have proposed that the strongest associations are deep inside the gene, the SNPs rs2413396 and rs5750250 and are more than $75 \mathrm{~Kb}$ from the start of transcription, and separated from it by a recombination hotspot. These independent associations could indicate either multiple functional polymorphisms, or a complex pattern of medium-range LD reflecting differing patterns of recombination in ancestral populations carrying the risk variant, or both. Considering the positional data, a splicing change seems a plausible functional variation. The SNP rs2413396, the strongest recessive association for FSGS, and rs4821480, in the strongest region of association in the earlier report, intron 23 , was predicted to modify splice-determining motifs. The risk variant for rs 2413396 decreases the predicted strength difference between the known splice site and a possible alternative by $20 \%$; although this is a small predicted effect, it is of interest given the strength of association for this SNP. A much stronger effect is predicted for the intron 23 SNP rs4821480; with the protective alleles of rs4821480, an alternate donor site has equal predicted strength as the standard site for the start of exon 24 , whereas with the risk allele the alternate motif is substantially weaker. Thus, the risk allele could plausibly abrogate alternate splicing. Although the possible splice variation is in frame, it contains two stop codons, indicating that it would have a knockout effect, eliminating the last 20 exons. This possible splice change cannot be the single primary functional effect, as rs4821480 is not significant when conditioned on rs 2413396 , but it could contribute to 
Table 2 MHY9 gene mutations in end stage renal disease

\begin{tabular}{|c|c|c|c|}
\hline $\begin{array}{l}\text { No. of } \\
\text { subjects }\end{array}$ & Patients studied & Observation & Reference \\
\hline 2 & Chinese patients & $\begin{array}{l}\text { Renal failure and thrombocytopenia, sensorineural hearing deficit } \\
\text { mutations in the gene encoding myosin heavy chain (MHY9) }\end{array}$ & 113 \\
\hline 751 & $\begin{array}{l}\text { African Americans with T2DM } \\
\text { with nephropathy, ESRD }\end{array}$ & $\begin{array}{l}\text { Polymorphisms in the nonmuscle myosin heavy chain } 9 \text { gene } \\
\text { (MYH9) are strongly associated with ESRD attributed to } \\
\text { hypertension }\end{array}$ & 112 \\
\hline 227 & $\begin{array}{l}\text { African Americans with T2DM } \\
\text { without nephropathy }\end{array}$ & & 112 \\
\hline 925 & $\begin{array}{l}\text { African Americans with } \\
\text { nondiabetic nephropathy (controls) }\end{array}$ & $\begin{array}{l}\text { T2DM-associated ESRD; coincident nephropathy have primary } \\
\text { MYH9-related kidney diseases (FSGS or global glomerulosclerosis) }\end{array}$ & 112 \\
\hline I2 families & $\begin{array}{l}\text { I } 2 \text { families with Epstein and } \\
\text { Fechtner syndromes }\end{array}$ & $\begin{array}{l}\text { Wide expression of MYH9 in fetal and mature kidneys, MYH9 } \\
\text { mutations associated with macrothrombocytopenia and } \\
\text { progressive nephropathy. MYH9 mutation associated with } \\
\text { hereditary deafness }\end{array}$ & 114 \\
\hline 175 & $\begin{array}{l}\text { African Americans with chronic } \\
\text { glomerulonephritis-associated } \\
\text { ESRD }\end{array}$ & $\begin{array}{l}\text { Hypertension-associated ESRD in African Americans is } \\
\text { associated with I } 3 \text { MYH9 polymorphism previously reported } \\
\text { as EI haplotypes; these patients are poor responders to }\end{array}$ & 112 \\
\hline 948 & Controls without kidney disease & antihypertensive drugs & \\
\hline 199 & African Americans: FSGS & Essential hypertension with ESRD associated with 2a MYH9 gene & 115 \\
\hline 222 & African American controls & & \\
\hline I & $\begin{array}{l}\text { 5-year-old girl with } \\
\text { macrothrombocytopenia }\end{array}$ & $\begin{array}{l}2 \text { mutations } \mathrm{C} 99 \mathrm{G} \rightarrow \mathrm{T} \mathrm{Cl03} \mathrm{C} \rightarrow \mathrm{G} \text { in exon I of } \mathrm{MYH} 9 \text { cause } \\
\text { Alport syndrome }\end{array}$ & 116 \\
\hline 19 families & $\begin{array}{l}\text { May-Hegglin anomaly, Sebastian } \\
12 \text { new cases }\end{array}$ & $\begin{array}{l}\text { These diseases are MHY9-related diseases and identify all patients } \\
\text { at risk of developing renal hearing and visual defects }\end{array}$ & 117 \\
\hline I & Epstein syndrome & Rapid progression of ESRD & 118 \\
\hline
\end{tabular}

Abbreviations: T2DM, type 2 diabetes mellitus; ESRD, end-stage renal disesase; FSGS, focal segmental glomerulosclerosis.

a more complex pattern of splice and possibly expression variation.

Authors have made an attempt to study the mechanisms by which the MYH9 variation reported here could exclusively or primarily affect the kidney. One possibility is that MYH9 expression in podocytes is characterized by unique mRNA splicing patterns, which might be affected by the SNPs described here. However, to this hypothesis there exists no evidence. An alternative hypothesis is that the special structure and function of podocytes places particular functional demands on the myosin-actin cytoskeleton in maintaining the podocyte foot processes so that minor changes in MYH9 protein structure, or MYH9 expression affecting the relative frequency of the different myosin heavy chain proteins, become critical. They have applied different statistical tools and have suggested that it is worth investigating whether, individuals with HIV disease who have susceptible combined genotypes of rs5750250 and rs11912763, initiation of antiretroviral therapy prior to the onset of kidney disease or with the appearance of microalbuminuria might reduce the burden of kidney disease among African descent individuals.

Franceschini et $\mathrm{al}^{121}$ studied the association between 20 MYH9 SNPs with kidney function (eGFR) and CKD (eGFR $\backslash 60 \mathrm{~mL} / \mathrm{min} / 1.73 \mathrm{~m}^{2}$ or renal replacement therapy or kidney transplant) using age-adjusted, sex-adjusted, and center-adjusted models and measured genotype within the variance component models. MYH9 SNPs were not significantly associated with kidney traits in additive or recessive genetic-adjusted models among American Indians. MYH9 haplotypes were also not significantly associated with kidney outcomes. In conclusion, common variants in MYH9 polymorphisms may not confer an increased risk of CKD in American Indian populations. Identification of the actual functional genetic variation responsible for the associations found in African Americans may clarify the lack of replication or same study is performed among Indians settled in the Indian subcontinent.

\section{The renin-angiotensin system}

Renin, angiotensinogen (AGT), angiotensin I-converting enzyme (ACE), chymase (CMA), angiotensin II type I receptor (AT1R), and aldosterone synthase (CYP11B2) all belong to the RAS.The RAS plays an important role in the regulation of blood pressure. A pathway where RAS is involved is illustrated in Figure 2. The octapeptide angiotensin (Ang) II is obtained by the proteolytic cleavage of the larger precursor molecule AGT, which is primarily synthesized in the liver and to a lesser extent, in the kidney, brain, heart, adrenal, 
fat, and vascular walls. The human $A G T$ cDNA is 1,455 nucleotides long and codes for a 485 amino acid protein. AGT is first converted by renin to produce the decapeptide AngI. Ang I is then converted to Ang II by the removal of a C-terminal dipeptide by ACE. In experimental and clinical studies, chronic administration of RAS inhibitors has proven effective in lowering blood pressure. Therefore, genes that encode components of the RAS are potential candidate genes that may play a role in the regulation of blood pressure.

The plasma concentration of AGT is close to the Michaelis constant of the enzymatic reaction between renin and AGT. Increase in the plasma AGT levels can lead to a parallel increase in the formation of Ang II that may ultimately result in hypertension. There is a significant relationship between plasma concentration of AGT and blood pressure in human subjects. Elevation of blood pressure is observed in transgenic animals that overexpress the $A G T$ gene $^{122}$ and reduction of blood pressure seen in $A G T$ gene-knockout mice. ${ }^{123}$ Kim et al have introduced up to 4 copies of the $A G T$ gene in mice, with each copy of the gene resulting in a successive increase in blood pressure; ${ }^{124}$ these results directly demonstrated that small increase in plasma AGT levels can quantitatively influence the fine control of renal vascular resistance and increase blood pressure in a gene dose-dependent manner.
A similar ACE gene duplication in mice led to an increase in plasma ACE levels but no increase in blood pressure, ${ }^{125}$ which reflects the importance of greater $A G T$ gene in human hypertension.

Recently, many SNPs have been detected in the ACE gene and the search for the location of functional polymorphisms became a topic of extensive investigation. Nevertheless, association studies on the I/D polymorphism and clinical outcomes continued, mostly with conflicting results. It has been suggested that a functional polymorphism is most likely located between intron 18 and the $3^{\prime}$ UTR region of the gene. The potential existence of another functional polymorphism in the 5' UTR, however, cannot be excluded. ${ }^{126}$ The ACE insertion/deletion (I/D) polymorphism has received much attention in pharmacogenetic research because observed variations in response to ACE inhibitors might be associated with this polymorphism. Pharmacogenetic testing raises the hope to individualize ACE inhibitor therapy in order to optimize its effectiveness and to reduce adverse effects for genetically different subgroups. However, the extent of its effect modification in patients treated with ACE inhibitors remains inconclusive.

Somatic ACE consists of an intracellular domain, a transmembrane domain and two similar extracellular domains:

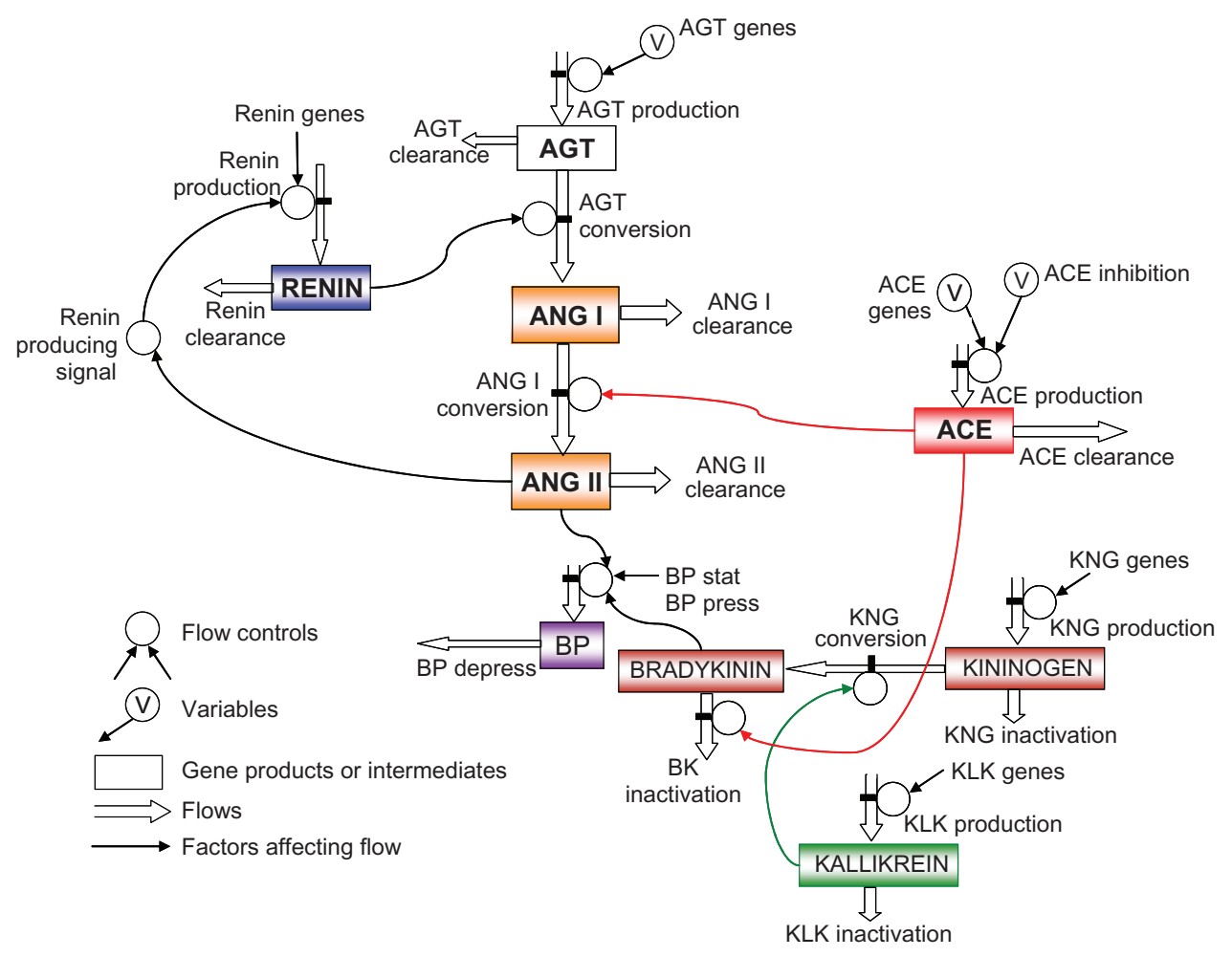

Figure 2 Role of ACE gene in blood pressure control. Figure demonstrates the gene products and their variables and factors affecting the ACE production clearance and inhibition etc. 
the amino or $\mathrm{N}$ domain and the carboxy or $\mathrm{C}$ domain. The structure of the ACE gene is the result of gene duplication; the $\mathrm{N}$ and $\mathrm{C}$ domains are similar in sequence, and the homologous exons encoding the $\mathrm{N}$ and $\mathrm{C}$ domains (exons 4-11 and 17-24, respectively) are similar in size and have similar codon phases at exon-intron boundaries. Each of the domains contains a catalytically active site characterized by a consensus zincbinding motif (HEXXH in the single-letter amino acid code, where $\mathrm{X}$ is any amino acid) and a glutamine near the carboxyl terminus binds to zinc; ACE and its homologs, therefore, make up the M2 gluzincin family. ${ }^{127}$

Most of the studies on IgAN in adults with ACE gene deletion/insertion $(D / I)$ reported that genotype $D D$ is a poor prognosis; however, the results are contradictory, which could be explained by different sample size (48-204 patients) included in different studies or there may be variable proportions of severe forms, and unrecognized stratification of the populations, different end points, and interference of reninangiotensin inhibitory drugs.

A recent meta-analysis performed by Niu et $\mathrm{al}^{128}$ showed that associations of ACE gene insertion/deletion (I/D) polymorphism with T2D have been inconsistent with the positive, null, and negative results. They collected the case - control studies from MEDLINE, EMBASE and Web of Science as of December 10, 2009. A total of 14 studies with 1,985 patients with T2D and 4,602 controls were finally identified. Random-effects model was applied irrespective of betweenstudy heterogeneity to these 1985 patients with T2D and 4602 controls. Study quality was assessed in duplicate. Compared with ACE I allele, presence of D allele conferred a significant increased risk for T2D $(\mathrm{OR}=1.33 ; 95 \% \mathrm{CI}$ : $1.10-1.61$; $P=0.003)$. This trend was potentiated after comparing homozygotes of D allele with I allele with a $90 \%$ increased risk $(P=0.0008)$. Carriers of $\mathrm{D}$ allele had a moderate increased risk for T2D compared with the II genotype carriers $(\mathrm{OR}=1.34$; 95\% CI: $1.04-1.72 ; P=0.02)$, whereas under recessive model, this effect was significantly enhanced $(\mathrm{OR}=1.73$; 95\% CI: $1.26-2.38 ; P=0.0008)$. Subgroup analyses indicated significant association for population-based study design only among populations from Africa and Europe ancestries rather than from Asia ancestry. No publication bias was observed using the fail-safe number at the level of 0.05 . Their results demonstrated that ACE D allele was significantly associated with an increased risk of T2D, and this effect appeared to be additive. Moreover, this association was more prominent for population-based studies among Africans and Caucasians. This is an important review indicating the importance of population stratification in association studies.
The risk of ESRD is greater among Mexican Americans and blacks. ${ }^{129}$ The most common renal pathological change associated with nonmalignant hypertension is hyalinization and sclerosis of the walls of preglomerular (afferent) arterioles, referred to as hypertensive nephrosclerosis. ${ }^{130}$ Familial aggregation of ESRD, including hypertensive ESRD, has been documented both in blacks ${ }^{131}$ and in whites. ${ }^{132}$ In pursuit of human renal failure susceptibility genes, Freedman and colleagues ${ }^{133}$ conducted linkage studies in black families affected by ESRD. Markers on chromosome $10 \mathrm{q}$ spanning the homologous region of the rodent $R f-1$ gene did not show evidence for linkage with ESRD; however, two adjacent markers on chromosome $10 \mathrm{p}$ approached significance in sib pairs with nondiabetic ESRD. ${ }^{134}$ In other samples, evidence of linkage approached significance for the gene coding for TGF- $\beta 2^{133}$ and evidence of statistically significant association was found for alleles at the plasma kallikrein gene ${ }^{135}$ However, the most direct evidence of renal failure susceptibility genes comes from studies of the fawn-hooded rat. ${ }^{136}$ Two genes, designated $R f-1$ and $R f-2$, were determined to contribute substantially to the development of renal impairment. $R f-1$ explained $40 \%$ of the genetic component of renal impairment but showed no significant linkage or association with blood pressure levels, suggesting that the $R f-1$ locus acts through a mechanism other than by increasing blood pressure. The second gene, $R f-2$, mapped to a locus that influences blood pressure, as well as influence renal damage through a mechanism different from blood pressure. ${ }^{13}$ Angiotensin II type 1 receptor (AT1R) polymorphisms may influence intrarenal angiotensin II activity. Healthy Caucasian carriers of the A1166C polymorphism showed 7\% lower basal GFR and $17 \%$ lower basal renal plasma flow, as well as enhanced GFR following treatment with the AT1R blocker losartan. ${ }^{137}$ Rate of progression to ESRD in patients with nephropathies of various etiologies was more rapid in individuals homozygous for the AT1R A1166C polymorphism. ${ }^{138}$ Worobey et al have found a similar association between homozygosity for the AT1R A1166C polymorphism and an accelerated rate of renal function decline. ${ }^{136}$

\section{Angiotensinogen gene}

The M235T polymorphism within the angiotensinogen (AGT) gene was associated with interstitial nephritis, where $235 \mathrm{t}$ allele was transmitted significantly more frequently than expected and may thus play a significant role in progression of disease in these patients. ${ }^{139}$ The A6G gene variant of AGT gene is associated with increased susceptibility to 
essential hypertension with or without T2DM in Malaysian subjects. ${ }^{140}$

Aldosterone synthase (CYP11B2 gene) is independent of angiotensin II and is found to be associated with renal dysfunction and glomerulosclerosis in remnant kidney rat models and glomerular hyperfiltration in humans with primary aldosteronism. ${ }^{141}$ Earlier studies of aldosterone synthase gene polymorphisms and hypertension have been mixed, ${ }^{142}$ and no prior study has found an association between the aldosterone synthase polymorphism and progression of renal disease. ${ }^{143}$

Adducin is a membrane cytoskeleton-associated protein consisting of an $\alpha$ subunit and either a $\beta$ or $\gamma$ subunit that promotes the assembly of the spectrin - actin network. In rats and humans, mutations of the $\alpha$-adducin subunit lead to the stimulation of $\mathrm{Na}(+), \mathrm{K}(+)$-ATPase activity in renal tubular cells, increased renal $\mathrm{Na}(+)$ reabsorption and, subsequently, low-renin hypertension. A familial aggregation study demonstrated that low-renin hypertension was associated with the $\alpha$-adducin G460W polymorphism. ${ }^{144}$ In a study of 260 ESRD patients matched to controls, the time from diagnosis with renal disease to onset of ESRD was shorter for patients homozygous for tryptophan (Trp) at the glycine to tryptophan (G460W) polymorphism vs those homozygous for glycine (Gly). ${ }^{145}$ The $\alpha$-adducin Trp polymorphism has been associated with lower GFR in essential hypertensive individuals when on a low-sodium diet but not when on a normal-high sodium diet. ${ }^{146}$ It was postulated that the Trp polymorphism may be associated with increased GFR, which balances the increased sodium reabsorption. ${ }^{150}$ This hyperfiltration might lead to steeper decline in renal function over time, especially in the presence of renal disease. In contrast, it has been seen there might be protective effect of the $\alpha$-adducin Trp polymorphism on renal function decline. Perhaps this polymorphism, which confers a greater sodium resorptive capacity, may protect against volume depletion and subsequent stimulation of the RAS system. ${ }^{147}$ Based upon the knowledge of genetic polymorphism, various therapeutic approaches have been tried with some success.

\section{Future directions}

ESRD seems to be the inevitable end point for a wide spectrum of renal conditions. The rate at which this point is reached is highly variable and hence offers many possibilities for therapeutic intervention. Even in conditions where prevention and early diagnosis seems difficult, the ability to predict the rate of progression and identify rapid and slow progressors would help in improving therapy. An important issue is that identification of affected individuals in some of these conditions requires an invasive procedure and replacement with a noninvasive genetic test would be invaluable. This review has illustrated some important challenges regarding the use of genetic approaches to investigate human diseases in which genetic contribution is complex. However, several powerful resources have been assembled around the world, and with the rapid advances in methodologies there is a hope that some answers will emerge and will help patients with ESRD.

\section{Disclosure}

The authors report no conflicts of interest in this work.

\section{References}

1. Satko SG, Freedman BI, Moossavi S. Genetic factors in end-stage renal disease. Kidney Int. 2005;67:S46-S49.

2. Wattanakit K, Coresh J, Muntner P, Marsh J, Folsom AR. Cardiovascular risk among adults with chronic kidney disease, with or without prior myocardial infarction. J Am Coll Cardiol. 2006;48: $1183-1189$.

3. Hsu CC, Kao WH, Coresh J, et al. Apolipoprotein E and progression of chronic kidney disease. JAMA. 2005;293:2892-2899.

4. Fredman D, White SJ, Potter S, Eichler EE, Den Dunnen JT, Brookes AJ. Complex SNP-related sequence variation in segmental genome duplications. Nat Genet. 2004;36:861-866.

5. Kiliś-Pstrusińska K. Genetic factors in the development and progression of chronic kidney disease. Postepy Hig Med Dosw. 2010;64:50-57.

6. Donnelly P. Progress and challenges in genome-wide association studies in humans. Nature. 2008;456:728-731.

7. Loannidis JP. Prediction of cardiovascular disease outcomes and established cardiovascular risk factors by genome-wide association markers. Circ Cardiovasc Genet. 2009;2:7-15.

8. DeWan AT, Arnett DK, Atwood LD, et al. A genome scan for renal function among hypertensives: the HyperGEN study. Am J Hum Genet. 2001;68:136-144.

9. Bowden DW, Colicigno CJ, Langefeld CD, et al. A genome scan for diabetic nephropathy in African Americans. Kidney Int. 2004;66: $1517-1526$.

10. Freedman BI, Beck SR, Rich SS, et al. A genome-wide scan for urinary albumin excretion in hypertensive families. Hypertension. $2003 ; 42: 291-296$.

11. Hunt SC, Coon H, Hasstedt SJ, et al. Linkage of serum creatinine and glomerular filtration rate to chromosome 2 in Utah pedigrees. $\mathrm{Am} \mathrm{J}$ Hypertens. 2004;17:511-515.

12. Fox CS, Larson MG, Keyes MJ, et al; for the Framingham Heart Study. Kidney function is inversely associated with coronary artery calcification in men and women free of cardiovascular disease. Kidney Int. 2004;66:2017-2021.

13. Brown DM, Provoost AP, Daly MJ, Lander ES, Jacob HJ. Renal disease susceptibility and hypertension are under independent genetic control in the fawn-hooded rat. Nat Genet. 1996;12:44-51.

14. Freedman BI, Rich SS, Yu H, Roh BH, Bowden DW. Linkage heterogeneity of end-stage renal disease on human chromosome 10. Kidney Int. 2002;62:770-774.

15. Hunt SC, Hasstedt SJ, Coon H, et al. Linkage of creatinine clearance to chromosome 10 in Utah pedigrees replicates a locus for end-stage renal disease in humans and renal failure in the fawn-hooded rat. Kidney Int. 2002;62:1143-1148.

16. Foley RN, Murray AM, Li S, et al. Chronic kidney disease and the risk for cardiovascular disease, renal replacement, and death in the United States Medicare population, 1998 to 1999. J Am Soc Nephrol. 2005;16:489-495. 
17. Arar NH, Voruganti VS, Nath SD, et al. A genome-wide search for linkage to chronic kidney disease in a community-based sample: the SAFHS. Nephrol Dial Transplant. 2008;10:3184-3191.

18. Chen G, Adeyemo AA, Zhou J, et al. A genome-wide search for linkage to renal function phenotypes in West Africans with type 2 diabetes. Am J Kidney Dis. 2007;49:394-400.

19. Leon JM, Freedman BI, Miller MB, et al. Genome scan of glomerular filtration rate and albuminuria: the HyperGEN study. Nephrol Dial Transplant. 2007;22:763-771.

20. Sale MM, Freedman BI. Genetic determinants of albuminuria and renal disease in diabetes mellitus. Nephrol Dial Transplant. 2006;21: 13-16.

21. Joseph LJ, Chang L, Stamenkovich CD, Sukhatme VP. Complete nucleotide and deduced amino acid sequences of human and murine preprocathepsin L: an abundant transcript induced by transformation of fibroblasts. J Clin Invest. 1988;1621-1629

22. Grimm C, Kraft R, Sauerbruch S, Schultz G, Harteneck C. Molecular and functional characterization of the melastatin-related cation channel TRPM3. J Biol Chem. 2003;278:21493-21501.

23. Reiser J, Polu KR, Möller CC, et al. TRPC6 is a glomerular slit diaphragm-associated channel required for normal renal function. Nat Genet. 2005;37:739-744.

24. Beerman I, Novak J, Wyatt RJ, Julian BA, Gharavi AG. The genetics of IgA nephropathy. Nat Clin Pract Nephrol. 2010;3:325-338.

25. Hall YN, Fuentes EF, Chertow GM, Olson JL. Race/ethnicity and disease severity in IgA nephropathy. BMC Nephrol. 2004;5:10.

26. Casiro OG, Stanwick RS, Walker RD. The prevalence of IgA nephropathy in Manitoba Native Indian children. Can J Public Health. 1988;79:308-310.

27. Julian BA, Quiggins PA, Thompson JS, Woodford SY, Gleason K, Wyatt RJ. Familial IgA nephropathy. Evidence of an inherited mechanism of disease. N Engl J Med. 1985;312:202-208.

28. Levy M. Familial cases of Berger's disease and anaphylactoid purpura: more frequent than previously thought. Am J Med. 1989;87: 246-248.

29. Scolari F, Amoroso A, Savoldi S, et al. Familial clustering of IgA nephropathy: further evidence in an Italian population. Am J Kidney Dis. 1999;33:857-865.

30. Paterson AD, Liu XQ, Wang K, Magistroni R, et al. Genome-wide linkage scan of a large family with $\operatorname{IgA}$ nephropathy localizes a novel susceptibility locus to chromosome 2q36. J Am Soc Nephrol. 2007; 18:2408-2415.

31. O'Connell PJ, Ibels LS, Thomas MA, Harris M, Eckstein RP. Familial IgA nephropathy: a study of renal disease in an Australian aboriginal family. Aust N Z J Med. 1987;17:27-33.

32. Karnib HH, Sanna-Cherchi S, Zalloua PA, et al. Characterization of a large Lebanese family segregating IgA nephropathy. Nephrol Dial Transplant. 2007;22:772-777.

33. Beerman I, Novak J, Wyatt RJ, Julian BA, Gharavi AG. The genetics of IgA nephropathy. Nat Clin Pract Nephrol. 2007;3:325-338.

34. Ohtsubo S, Iida A, Nitta K, Tanaka T, et al. Association of a single-nucleotide polymorphism in the immunoglobulin mu-binding protein 2 gene with immunoglobulin a nephropathy. J Hum Genet. 2005;50:30-35.

35. Smith AC, de Wolff JF, Molyneux K, Feehally J, Barratt J. O-glycosylation of serum IgD in IgA nephropathy. J Am Soc Nephrol. 2006;17: 1192-1199.

36. Gharavi AG, Moldoveanu Z, Wyatt RJ, et al. Aberrant IgA1 glycosylation is inherited in familial and sporadic IgA nephropathy. J Am Soc Nephrol. 2008;19:1008-1014.

37. Lin X, Ding J, Zhu L, Shi S, Jiang L, Zhao M, et al. Aberrant galactosylation of IgA1 is involved in the genetic susceptibility of Chinese patients with IgA nephropathy. Nephrol Dial Transplant. 2009;24: 3372-3375.

38. Suzuki H, Fan R, Zhang Z, Brown R, et al. Aberrantly glycosylated IgA1 in IgA nephropathy patients is recognized by IgG antibodies with restricted heterogeneity. J Clin Invest. 2009;119:1668-1677.
39. Frimat L, Philippe C, Maghakian MN, et al. Polymorphism of angiotensin converting enzyme, angiotensinogen and angiotensin II type 1 receptor genes and end-stage renal failure in IgA nephropathy. IGARAS: a study of 274 men. J Am Soc Nephrol. 2000;11: 2062-2067.

40. José CRodríguez-Pérez, Antonio Macías-Reyes, Jiménez-Sosa A, et al. A synergistic association of ACE I/D and eNOS G894T gene variants with the progression of immunoglobulin a nephropathy - A pilot study. Am J Nephrol. 2009;30:303-309.

41. Berthoux FC, Berthoux P, Mariat C, Thibaudin L, Afiani A, Linossier MT. $\mathrm{CC}$-chemokine receptor five gene polymorphism in primary IgA nephropathy: the 32 bp deletion allele is associated with late progression to endstage renal failure with dialysis. Kidney Int. 2006;69:565-572.

42. Li YJ, Du Y, Li CX, Guo H, et al. Family-based association study showing that immunoglobulin A nephropathy is associated with the polymorphisms $2093 \mathrm{C}$ and $2180 \mathrm{~T}$ in the $3^{\prime}$ untranslated region of the Megsin gene. J Am Soc Nephrol. 2004;15:1739-1743.

43. Lim CS, Kim SM, Oh YK, Joo KW, Kim YS, Han JS, et al. Megsin 2093T-2180C haplotype at the 3' untranslated region is associated with poor renal survival in Korean IgA nephropathy patients. Clin Nephrol. 2008;70:101-109.

44. Xu G, He Q, Shou Z, et al. NA1/NA2 heterozygote of Fcgr3b is a risk factor for progression of IgA nephropathy in Chinese. J Clin Lab Anal. 2007;21:298-302.

45. Li GS, Zhang H, Lü JC, Shen Y, Wang HY. Variants of C1GALT1 gene are associated with the genetic susceptibility to IgA nephropathy. Kidney Int. 2007;71:448-453.

46. Alarcón GS, McGwin G Jr, Bartolucci AA, et al; for LUMINA Study Group. Lupus in minority populations, nature versus nurture. Systemic lupus erythematosus in three ethnic groups. IX. Differences in damage accrual. Arthritis Rheum. 2001;44:2797-2806.

47. Graham RR, Kozyrev SV, Baechler EC, et al. A common haplotype of interferon regulatory factor 5 (IRF5) regulates splicing and expression and is associated with increased risk of systemic lupus erythematosus. Nat Genet. 2006;38:550-555.

48. Karassa FB, Trikalinos TA, Ioannidis JPA. Role of the Fcc receptor IIa polymorphism in susceptibility to systemic lupus erythematosus and lupus nephritis. Arthritis Rheum. 2002;46:1563-1571.

49. Aitman TJ, Dong R, Vyse TJ, et al. Copy number polymorphism in Fcgr3 predisposes to glomerulonephritis in rats and humans. Nature. 2006;439:851-855.

50. Alarcón GS, Roseman JM, McGwin G Jr, et al; for LUMINA Study Group. Systemic lupus erythematosus in three ethnic groups: XX. Damage as predictor of further damage. Rheumatology. 2004;43:202-205.

51. International Consortium for Systemic Lupus Erythematosus Genetics (SLEGEN), Harley JB, Alarcón-Riquelme ME, Criswell LA, et al. Genome-wide association scan in women with systemic lupus erythematosus identifies susceptibility variants in ITGAM, PXK, KIAA1542 and other loci. Nat Genet. 2008;40:204-210.

52. Hom G, Graham RR, Modrek B, et al. Association of systemic lupus erythematosus with C8orf13-BLK and ITGAM-ITGAX. $N$ Engl J Med. 2008;358:900-909.

53. Kozyrev SV, Abelson AK, Wojcik J, et al. Functional variants in the B-cell gene BANK1 are associated with systemic lupus erythematosus. Nat Genet. 2008;40:211-216.

54. Nath SK, Han S, Kim-Howard X, et al. A nonsynonymous functional variant in integrin-alpha(M) (encoded by ITGAM) is associated with systemic lupus erythematosus. Nat Genet. 2008;40:152-154.

55. Graham RR, Cotsapas C, Davies L, et al. Genetic variants near TNFAIP3 on $6 \mathrm{q} 23$ are associated with systemic lupus erythematosus. Nat Genet. 2008;40:1059-1061.

56. Musone SL, Taylor KE, Lu TT, et al. Multiple polymorphisms in the TNFAIP3 region are independently associated with systemic lupus erythematosus. Nat Genet. 2008;40:1062-1064.

57. Webb R, Merrill JT, Kelly JA, et al. A polymorphism within IL21R confers risk for systemic lupus erythematosus. Arthritis Rheum. 2009;60:2402-2407. 
58. Jacob CO, Zhu J, Armstrong DL, et al. Identification of IRAK1 as a risk gene with critical role in the pathogenesis of systemic lupus erythematosus. Proc Natl Acad Sci U S A. 2009;106:6256-6261.

59. Liu K, Li QZ, Delgado-Vega AM, et al; for Italian Collaborative Group; German Collaborative Group; Spanish Collaborative Group; Argentinian Collaborative Group; SLEGEN Consortium, Wakeland EK, Alarcón-Riquelme ME, Mohan C. Kallikrein genes are associated with lupus and glomerular basement membrane-specific antibody-induced nephritis in mice and humans. J Clin Invest. 2009;119:911-923.

60. Gateva V, Sandling JK, Hom G, et al. A large-scale replication study identifies TNIP1, PRDM1, JAZF1, UHRF1BP1 and IL10 as risk loci for systemic lupus erythematosus. Nat Genet. 2009;41:1228-1233.

61. Han JW, Zheng HF, Cui Y, et al. Genome-wide association study in a Chinese Han population identifies nine new susceptibility loci for systemic lupus erythematosus. Nat Genet. 2009;41:1234-1237.

62. Yang W, Ng P, Zhao M, et al. Population differences in SLE susceptibility genes: STAT4 and BLK, but not PXK, are associated with systemic lupus erythematosus in Hong Kong Chinese. Genes Immun. 2009;10:219-226.

63. Yang W, Shen N, Ye DQ, et al; for Asian lupus genetics consortium (ALGC). Genome-wide association study in Asian populations identifies variants in ETS1 and WDFY4 associated with systemic lupus erythematosus. PLoS Genet. 2010;6(2):e1000841.

64. Yang W, Zhao M, Hirankarn N, et al. ITGAM is associated with disease susceptibility and renal nephritis of systemic lupus erythematosus in Hong Kong Chinese and Thai. Hum Mol Genet. 2009;18:2063-2070.

65. Janssen B, Hohenadel D, Brinkkoetter P, et al. Carnosine as a protective factor in diabetic nephropathy - association with a leucine repeat of the carnosinase gene CNDP1. Diabetes. 2005;54:2320-2327.

66. Savage DA, Patterson CC, Deloukas P, et al. Genetic association analyses of non-synonymous single nucleotide polymorphisms in diabetic nephropathy. Diabetologia. 2008;11:1998-2002.

67. Pezzolesi MG, Poznik GD, Mychaleckyj JC, et al. Krolewski genomewide association scan for diabetic nephropathy susceptibility genes in type 1 diabetes. Diabetes. 2009;58:1403-1410.

68. Leak TS, Langefeld CD, Keene KL, et al. Chromosome 7p linkage and association study for diabetes related traits and type 2 diabetes in an African-American population enriched for nephropathy. BMC Med Genet. 2010;11:22

69. Vats KR, Ishwad C, Singla I, et al. A locus for renal formations including, vesico-ureteric reflux on chromosome 13q33-34. J Am Soc Nephrol. 2006;17:1158-1167.

70. Feather SA, Malcolm S, Woolf AS, et al. Primary, nonsyndromic vesicoureteric reflux and its nephropathy is genetically heterogeneous, with a locus on chromosome 1. Am J Hum Genet. 2000;66:1420-1425.

71. Sanna-Cherchi S, Reese A, Hensle T, et al. Familial vesicoureteral reflux: testing replication of linkage in seven new multigenerational kindreds. J Am Soc Nephrol. 2000;16:1781-1787.

72. Freedman BI, Bowden DW, Rich SS, et al. A genome scan for all-cause end-stage renal disease in African Americans. Nephrol Dial Transplant. 2005;20:712-718.

73. Barai S, Bandopadhayaya GP, Bhowmik D, et al. Prevalence of vesicoureteral reflux in patients with incidentally diagnosed adult hypertension. Urology. 2004;63:1045-1048.

74. Kelly H, Molony CM, Darlow JM, et al. A genome-wide scan for genes involved in primary vesicoureteric reflux $J$ Med Genet. 2007;44:710-717.

75. Cordell HJ, Darlay R, Charoen P, et al; for Goodship and for the UK VUR Study Group. Whole-Genome linkage and association scan in primary, nonsyndromic vesicoureteric. Reflux J Am Soc Nephrol. 2010;21:113-123.

76. Weng PL, Sanna-Cherchi S, Hensle T, et al. A recessive gene for primary vesicoureteral reflux maps to chromosome 12p11-q13. JASN Express. 2009;20:1633-1640.

77. Harris PC, Bae K, Rossetti S, Torres VE, et al. Cyst number but not the rate of cystic growth is associated with the mutated gene in ADPKD. J Am Soc Nephrol. 2006;17:3013-3019.
78. Consugar M, Rossetti S, Anderson S, et al. $P K D 3$ revisited with improved $P K D 1$ and $P K D 2$ haplotyping and mutation screening [abstract]. J Am Soc Nephrol. 2005;16:358A.

79. Martin J, Han C, Gordon LA, et al. The sequence and analysis of duplication-rich human chromosome 16. Nature. 2004;432:988-994.

80. Rossetti S, Chauveau D, Walker D, et al. A complete mutation screen of the ADPKD genes by DHPLC. Kidney Int. 2002;61:1588-1599.

81. Hayashi T, Mochizuki T, Reynolds DM, Wu G, Cai Y, Somlo S. Characterization of the exon structure of the polycystic kidney disease 2 gene (PKD2). Genomics. 1997;44:131-136.

82. Ward CJ, Hogan MC, Rossetti S, et al. The gene mutated in autosomal recessive polycystic kidney disease encodes a large, receptor-like protein. Nat Genet. 2002;30:259-269.

83. Sharp AM, Messiaen LM, Page G, et al. Comprehensive genomic analysis of PKHD1 mutations in ARPKD cohorts. J Med Genet. 2005;42:336-349.

84. Losekoot M, Haarloo C, Ruivenkamp C, White SJ, Breuning MH, Peters DJ. Analysis of missense variants in the PKHD1-gene in patients with autosomal recessive polycystic kidney disease (ARPKD). Hum Genet. 2005;188:185-206.

85. Consugar MB, Anderson SA, Rossetti S, et al. Haplotype analysis improves molecular diagnostics of autosomal recessive polycystic kidney disease. Am J Kidney Dis. 2005;45:77-87.

86. Zerres K, Senderek J, Rudnik-Schoneborn S, et al. New options for prenatal diagnosis in autosomal recessive polycystic kidney disease by mutation analysis of the PKHD1 gene. Clin Genet. 2004;66:53-57.

87. Mrug M, Li R, Cui X, Schoeb TR, Churchill GA, Guay-Woodford LM. Kinesin family member 12 is a candidate polycystic kidney disease modifier in the cpk mouse. J Am Soc Nephrol. 2005;16:905-916.

88. Hiesberger T, Bai Y, Shao X, et al. Mutation of hepatocyte nuclear factor- $1 \mathrm{~b}$ inhibits $P k h d 1$ gene expression and produces renal cysts in mice. $J$ Clin Invest. 2004;113:814-825.

89. Song X, Giovanni VD, He N, Wang K, Ingram A, Rosenblum ND, et al. Systems biology of autosomal dominant polycystic kidney disease (ADPKD): computational identification of gene expression pathways and integrated regulatory networks. Hum Mol Genet. 2009; 18:2328-2343.

90. Saunier S, Calado J, Heilig R, Silbermann F, Benessy F, Morin G, et al. A novel gene that encodes a protein with a putative src homology 3 domain is a candidate gene for familial juvenile nephronophthisis. Hum Mol Genet. 1997;6:2317-2323.

91. Otto EA, Schermer S, Obara T, et al. Inversin mutations cause nephronophthisis type 2, linking renal cystic disease to the function of primary cilia and left-right axis determination. Nat Genet. 2003;34:413-420.

92. Olbrich H, Fliegauf M, Hoefele J, et al. Mutations of NPHP3 cause nephronophthisis, tapeto-retinal degeneration and hepatic fibrosis. Nat Genet. 2003;34:455-459.

93. Mollet G, Salomon R, Gribouval O, et al. The gene mutated in juvenile nephronophthisis type 4 encodes a novel protein that interacts with nephrocystin. Nat Genet. 2002;32:300-305.

94. Otto EA, Loeys B, Khanna H, et al. Nephrocystin-5, a ciliary IQ domain protein, is mutated in Senior-Loken syndrome and interacts with RPGR and calmodulin. Nat Genet. 2005;37:282-288.

95. Sayer JA, Otto EA, O'Toole JF, et al. The centrosomal protein nephrocystin-6 is mutated in Joubert syndrome and activates transcription factor ATF4. Nat Genet. 2006;38:674-681.

96. Konrad M, Saunier S, Calado J, Gubler MC, Broyer M, Antignac C. Familial juvenile nephronophthisis. J Mol Med. 1998;76:310-316.

97. Donaldson JC, Dise RS, Ritchie MD, Hanks SK. Nephrocystin-conserved domains involved in targeting to epithelial cell-cell junctions, interaction with filamins, and establishing cell polarity. $J$ Biol Chem. 2002;277:29028-29035.

98. Fiskerstrand T, Houge G, Sund S, Scheie D, Leh S, Boman H, et al. Identification of a gene for renal-hepatic-pancreatic dysplasia by microarray-based homozygosity mapping. J Mol Diagn. 2010;12:125-131.

99. Hildebrandt F, Attanasio M, Otto E. Nephronophthisis disease mechanisms of a ciliopathy. J Am Soc Nephrol. 2009;20:23-35. 
100. Brown EJ, Schlöndorff JS, Becker DJ, et al. Mutations in the formin gene INF2 cause focal segmental glomerulosclerosis. Nat Genet. 2010;42:72-76

101. Provaznikova D, Geierova1 V, Kumstyrova T, et al. Clinical manifestation and molecular genetic characterization of MYH9 disorders. Platelets. 2009;20:289-296.

102. D'Apolito M, Guarnieri V, Boncristiano M, Zelante L, Savoia A. Cloning of the murine non-muscle myosin heavy chain IIA gene ortholog of human MYH9 responsible for May-Hegglin, Sebastian, Fechtner, and Epstein syndromes. Gene. 2002;286:215-222.

103. Marini M, Bruschi M, Pecci A, et al. Non-muscle myosin heavy chain IIA and IIB interact and co-localize in living cells: relevance for MYH9-related disease. Int J Mol Med. 2006;17:729-736.

104. Singh N, Nainani N, Arora P, Venuto RC. CKD in MYH9-related disorders. Am J Kidney Dis. 2009;54:732-740.

105. Burt RA, Collinge JE, Kile BT. Description of a novel mutation leading to MYH-9-related disease. Thromb Res. 2008;122:861-863.

106. de Rocco D, Heller PG, Girotto G, et al. A novel missense Ala95Asp mutation of the MYH9 gene. Platelets. 2009;20:598-602.

107. Sellers JR. Myosins. A diverse superfamily. Biochim Biophys Acta. 2000;1496:3-22.

108. Arrondel C, Vodovar N, Knebelmann B, et al. Expression of the nonmuscle myosin heavy chain IIA in the human kidney and screening for MYH9 mutation in Epstein and Fechtner syndromes. J Am Soc Nephrol. 2002;13:65-74.

109. Kao WH, Klag MJ, Meoni LA, et al. MYH9 is associated with nondiabetic end-stage renal disease in African Americans. Nat Genet. 2008;40:1185-1192.

110. Kopp JB, Smith MW, Nelwson GW, et al. MYH9 is a major-effect risk gene for focal segmental glomeulosclerosis. Nat Genet. 2008; 40:1145-1146.

111 Freedman BI, Kopp JB, Winkler CA, et al; for the HyperGEN Study. Polymorphisms in the nonmuscle myosin heavy chain 9 gene (MYH9) are associated with albuminuria in hypertensive African Americans. Am J Nephrol. 2009;29:626-632.

112. Freedman BI, Hicks PJ, Bostrom MA, et al. Polymorphisms in the nonmuscle myosin heavy chain 9 gene (MYH9) are strongly associated with end-stage renal disease historically attributed to hypertension in African Americans. Kidney Int. 2009; 75:736-745.

113. Freedman BI, Hicks PJ, Bostrom MA, et al. Non-muscle myosin heavy chain 9 gene MYH9 associations in African Americans with clinically diagnosed type 2 diabetes mellitus-associated ESRD. Nephrol Dial Transplant. 2009;24:3366-3371.

114. Arrondel C, Vodovar N, Knebelmann B, et al. Expression of the nonmuscle myosin heavy chain IIA in the human kidney and screening for MYH9 mutations in Epstein and Fechtner Syndromes. J Am Soc Nephrol. 2001;13:65-74.

115. Freedman BI, Sedor JR. Hypertension-associated kidney disease: perhaps no more. J Am Soc Nephrol. 2008;19:2047-2051.

116. Miyajima Y, Kunishima S. Identification of the first in cis mutations in MYH9 disorder. Eur J Haematol. 2008;82:288-291.

117. Seri M, Pecci A, Di Bari F, et al. MYH9-related disease: May-Hegglin anomaly, Sebastian syndrome, Fechtner syndrome, and Epstein syndrome are not distinct entities but represent a variable expression of a single illness. Medicine. 2003;82:203-215.

118. Epstein syndrome with rapid progression to end stage renal disease. Saudi J Kidney Dis Transpl. 2009;20:1076-1078.

119. Nelson GW, Freedman BI, Bowden DW, et al. Dense mapping of MYH9 localizes the strongest kidney disease associations to the region of introns 13 to 15. Hum Mol Genet. 2010;19:z1805-z1815.

120. Behar DM, Rosset S, Tzur S, et al. African ancestry allelic variation at the MYH9 gene contributes to increased susceptibility to non-diabetic end stage renal disease in Hispanics Americans. Hum Mol Genet. 2010;19:1816-1827.

121. Franceschini N, Voruganti VS, Haack K, et al. The association of the MYH9 gene and kidney outcomes in American Indians: the Strong Heart Family Study. Hum Genet. 2010;127:295-301.
122. Kimura S, Mullins JJ, Bunnemann B, et al. High blood pressure in transgenic mice carrying the rat angiotensinogen gene. EMBO J. 1992;11:821-827.

123. Tanimoto K, Sugiyama F, Goto Y, et al. Angiotensinogen-deficient mice with hypotension. J Biol Chem. 1994;269:31334-31337.

124. Kim HS, Krege JH, Kluckman KD, et al. Genetic control of blood pressure and the angiotensinogen locus. Proc Natl Acad Sci US A. 1995;92:2735-2739.

125. Krege JH, Kim HS, Moyer JS, et al. Angiotensin-converting enzyme gene mutations, blood pressures, and cardiovascular homeostasis. Hypertension. 1997;29:150-157.

126. Sayed-Tabatabaei FA, Oostra BA, Isaacs A, van Duijn CM, Witteman JCM. ACE polymorphisms. Circ Res. 2006;98:1123-1133.

127. Corvol P, Williams TA. Peptidyl-dipeptidase A/angiotensin 1-converting enzyme. In: Barrett AJ, Rawlings ND, Woessner JF, editors. Handbook of Proteolytic Enzymes. San Diego, CA: Academic Press; 1998: 1066-1076.

128. Niu W, Qi Y, Gao P, Zhu D. Angiotensin converting enzyme D allele is associated with an increased risk of type 2 diabetes: evidence from a meta-analysis. Endocr J. 2010;57:431-438.

129. Klag MJ, Whelton PK, Randall BL, Neaton JD, Brancati FL, Stamler J. End-stage renal disease in African- American and white men. JAMA. 1997;277:1293-1298.

130. Fogo A, Breyer JA, Smith MC, et al. Accuracy of the diagnosis of hypertensive nephrosclerosis in African Americans: a report from the African American study of kidney disease (AASK) trial. Kidney Int. 1997;51:244-252.

131. Freedman BI, Bowden DW, Rich SS, Appel RG. Genetic initiation of hypertensive and diabetic nephropathy. Am J Hypertens. 1998;11:251-257.

132. Spray BJ, Atassi NG, Tuttle AB, Freedman BI. Familial risk, age at onset, and cause of end-stage renal disease in white Americans. J Am Soc Nephrol. 1995;5:1806-1810.

133. Freedman BI, Yu H, Spray BJ, Rich SS, Rothschild CB, Bowden DW. Genetic linkage analysis of growth factor loci and end-stage renal disease in African Americans. Kidney Int. 1997;51:819-825.

134. Yu H, Sale M, Rich SS, et al. Evaluation of markers on human chromosome 10, including the homologue of the rodent Rf-1 gene for linkage to end-stage renal disease in blacks. Am J Kidney Dis. 1999;33:294-300.

135. Yu H, Bowden DW, Spray BJ, Rich SS, Freedman BI. Linkage analysis between loci in the renin-angiotensin axis and end-stage renal disease in African-Americans. J Am Soc Nephrol. 1996;7:2559-2564.

136. Worobey CC, Fisher ND, Cox D, Forman JP, Curhan GC. Genetic polymorphisms and the risk of accelerated renal function decline in women. PLoS One. 2009; 4:e4787.

137. Miller JA, Scholey JW. The impact of renin-angiotensin system polymorphisms on physiological and pathophysiological processes in humans. Curr Opin Nephrol Hypertens. 2004;13:101-106.

138. Coll E, Campos B, Gonzalez-Nunez D, Botey A, Poch E. Association between the A1166C polymorphism of the angiotensin II receptor type 1 and progression of chronic renal insufficiency. $J$ Nephrol. 2003;16:357-364.

139. Buraczynska M, Ksiazek P, Drop A, Zaluska W, Spasiewicz D, Ksiazek A. Genetic polymorphisms of the renin-angiotensin system in endstage renal disease. Nephrol Dial Transplant. 2006;21:979-983.

140. Ramachandran V, Ismail P, Stanslas J, Shamsudin N. Analysis of renin-angiotensin aldosterone system gene polymorphisms in malaysian essential hypertensive and type 2 diabetic subjects. Cardiovasc Diabetol. 2009;8:11.

141. Ribstein J, Du Cailar G, Fesler P, Mimran A. Relative glomerular hyperfiltration in primary aldosteronism. J Am Soc Nephrol. 2005;16:1320-1325.

142. Casiglia E, Tikhonoff V, Mazza A, Rynkiewicz A, Limon J, Caffi S, et al. C-344T polymorphism of the aldosterone synthase gene and blood pressure in the elderly: a population-based study. J Hypertens. 2005;23:1991-1996. 
143. Lovati E, Richard A, Frey BM, Frey FJ, Ferrari P. Genetic polymorphisms of the renin-angiotensin-aldosterone system in end-stage renal disease. Kidney Int. 2001;60:46-54.

144. Fisher ND, Hurwitz S, Jeunemaitre X, Hopkins PN, Hollenberg NK, Williams GH. Familial aggregation of low-renin hypertension. Hypertension. 2002;39:914-918.

145. Nicod J, Frey BM, Frey FJ, Ferrari P. Role of the alpha-adducin genotype on renal disease progression. Kidney Int. 2002;61: $1270-1275$.
146. Beeks E, van der Klauw MM, Kroon AA, Spiering W, Fuss-Lejeune MJ, de Leeuw PW. Alpha-adducin Gly460Trp polymorphism and renal hemodynamics in essential hypertension. Hypertension. 2004;44: 419-423.

147. Bianchi G, Manunta P. Adducin, renal intermediate phenotypes, and hypertension. Hypertension. 2004;44:394-395.

\section{Publish your work in this journal}

The Application of Clinical Genetics is an international, peer-reviewed open access journal that welcomes laboratory and clinical findings in the field of human genetics. Specific topics include: Population genetics; Functional genetics; Natural history of genetic disease; Management of genetic disease; Mechanisms of genetic disease; Counselling and ethical issues; Animal models; Pharmacogenetics; Prenatal diagnosis; Dysmorphology. The manuscript management system is completely online and includes a very quick and fair peer-review system, which is all easy to use. Visit http://www.dovepress.com/testimonials.php to read real quotes from published authors. 